\title{
PROCESS CHARACTERIZATION OF THE REACTIVE-ION ETCHING OF BOROSILICATE GLASS FOR MICROFLUIDIC CHANNELS
}

\author{
A Thesis \\ presented to \\ the Faculty of California Polytechnic State University, \\ San Luis Obispo
}

\author{
In Partial Fulfillment \\ of the Requirements for the Degree \\ Master of Science in Engineering, with Specialization in Materials Engineering \\ by \\ Ann Christine Huang
}

August 2010 
(C) 2010

Ann Christine Huang

ALL RIGHTS RESERVED 
COMMITTEE MEMBERSHIP

TITLE:

PROCESS CHARACTERIZATION OF THE REACTIVEION ETCHING OF BOROSILICATE GLASS FOR MICROFLUIDIC CHANNELS

AUTHOR:

ANN CHRISTINE HUANG

DATE SUBMITTED:

AUGUST 2010

COMMITTEE CHAIR: DR. LINDA S. VANASUPA, PROFESSOR

COMMITTEE MEMBER: DR. RICHARD N. SAVAGE, PROFESSOR

COMMITTEE MEMBER: DR. DAVID S. CLAGUE, PROFESSOR 


\begin{abstract}
Process Characterization of the Reactive-Ion Etching of Borosilicate Glass for Microfluidic Channels
\end{abstract}

Ann Christine Huang

The ability to work with small amounts of fluids is an emerging technology that can greatly benefit the biomedical industry, diagnostics, and society as a whole. Typically, these microfluidic devices are fabricated using polydimethylsiloxane (PDMS). Although it is optically clear, relatively inert, and easy to manipulate, PDMS does have its limitations. These include its tendency to swell when it comes in contact with certain chemicals and its hydrophobicity, which makes it difficult to analyze aqueous samples. Glass is an alternative material that addresses both issues. Etching is used to create these channels in glass. Wet etching procedures are typically isotropic and can lead to contamination. Dry etching is capable of producing anisotropic profiles, which is a desired trait. The purpose of this thesis was to characterize the process for the dry etching of borosilicate glass for microfluidic channels. Etch rate and surface roughness were studied, with partial pressure ratio $\left(\mathrm{SF}_{6}: \mathrm{O}_{2}\right)$ and $\mathrm{RF}$ power as the factors. After formulating a DOE, the glass wafers were etched, with aluminum as the etching mask. The etch rate and roughness were measured using a stylus profilometer and an ANOVA was generated to reveal any statistical significance between the treatments. There was a definite increase in etch rate with an increase in the $\mathrm{SF}_{6}: \mathrm{O}_{2}$ ratio as an increase in fluorine atoms etched more of the material. An increase in RF power led to an increase in etch rate due to ionic bombardment. From the ANOVA analysis, partial pressure ratio and RF power did not have a significant effect on roughness. This may have been due to the high variability from the small sample size. From the sample means, there may have been a trend present. An increase in $\mathrm{SF}_{6}: \mathrm{O}_{2}$ may have led to a higher roughness due to the amount of non-volatile compounds generated as more $\mathrm{F}$ atoms were available to react with the surface. For RF power, the sample means suggested that a higher RF power led to a lower roughness. If this were the case, it may have been due to the increase in ionic bombardment which was able to remove the non-volatile products that accumulated on the etched surface. Microscopic images of the etched surface revealed possible damage to the aluminum mask. The cause is unknown and could have occurred from various sources. 


\section{ACKNOWLEDGEMENTS}

This thesis would not be possible without the help and guidance of the following people:

Dr. Richard Savage, for his support and technical expertise related to the field of microfabrication. He was always available whenever I needed help for my project, particularly when it came to equipment issues. I am grateful that he introduced me to this project, provided the necessary materials, and gave me valuable insight. It has been a pleasure working with him in the clean room and taking his classes.

My advisor, Dr. Linda Vanasupa, for her guidance and advice. She has been helpful in identifying my strengths and weaknesses in my work and has allowed me to realize my true potential.

The statistics consultant, Dr. Ulric Lund for his immense help with the statistical analyses.

Dr. David Clague, for being on my committee and sharing his knowledge on microfluidics.

My colleagues at the Industrial Technology Research Institute (ITRI) in Hsinchu, Taiwan for introducing me to the world of MEMS and microfabrication. It is because of my work at ITRI that I chose this research topic. I am most grateful for the patience from my mentor, Ming-Hsien Wu (吳明憲). He took the time to explain a brand new concept to me, and for that, I feel extremely blessed.

Dylan Chesbro, for showing me how to use the RIE machine in the clean room and for providing encouragement while I completed this thesis.

My friends in MST along with the materials engineering department as a whole, for their guidance, friendship, and support during my stay at Cal Poly. I cannot imagine a better group of people to spend five years with.

And, lastly, my family for loving me even on my worst days. Their unwavering support is what motivates me to work hard every day and never give up hope. 


\section{Table of Contents}

List of Tables …………......................................................................................... vii

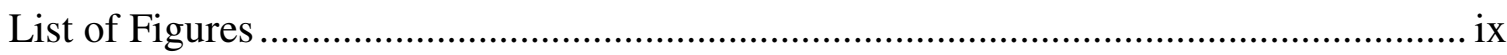

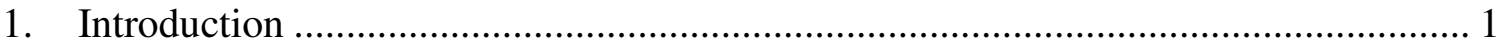

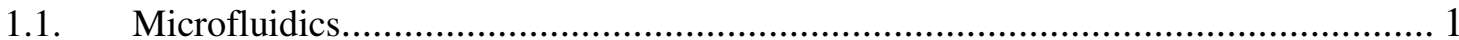

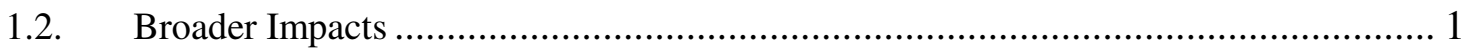

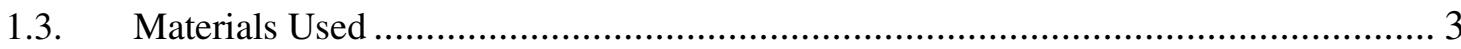

2. Technical Background ................................................................................... 5

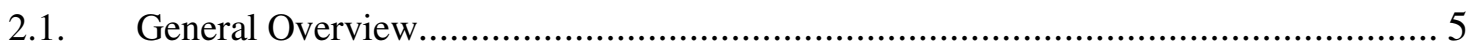

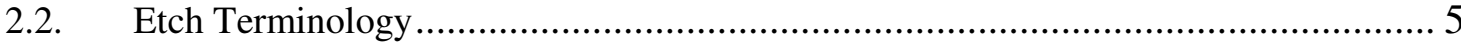

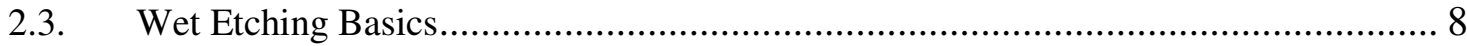

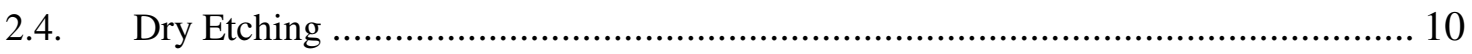

2.4.1. Physics and Chemistry of Dry Etching ............................................................. 10

2.4.2. Dry Etching Technology ................................................................................ 14

2.5. Materials: Glass Structure and Composition ........................................................ 16

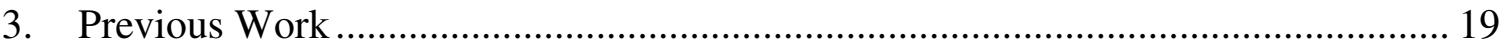

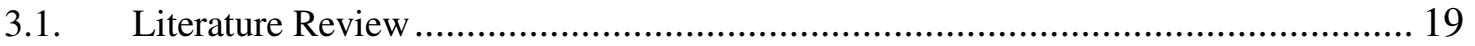

3.1.1. Dry Etching Equipment ………………………………............................... 19

3.1.2. Mask Materials.......................................................................................... 19

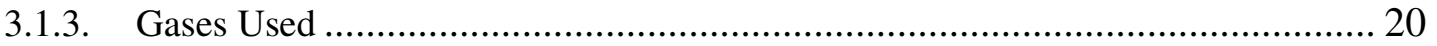

3.1.4. Glass Composition Effects ........................................................................... 21

3.1.5. Variation in Power, Bias Voltage, and Pressure ……………........................... 22

3.1.6. Aspect-Ratio-Dependent Etching................................................................... 23

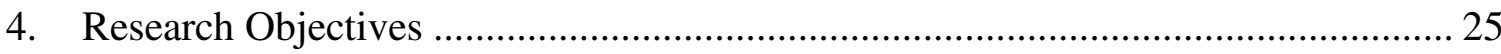

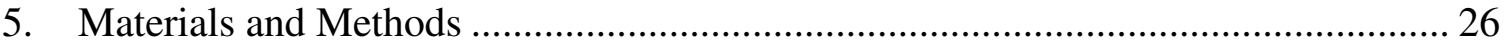

5.1. Fabrication and Processing ............................................................................... 26

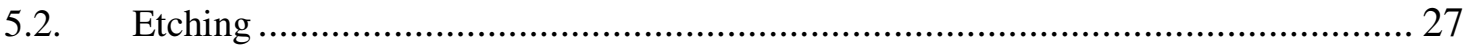

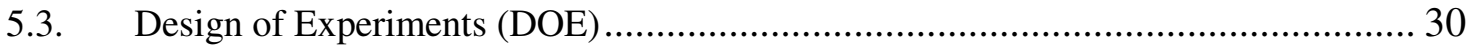

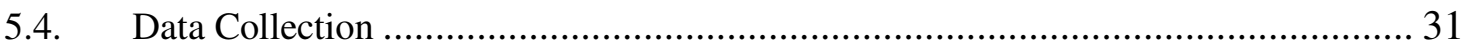

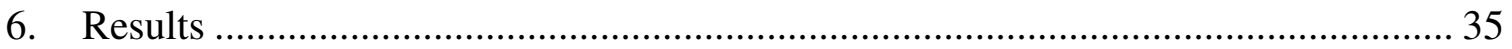




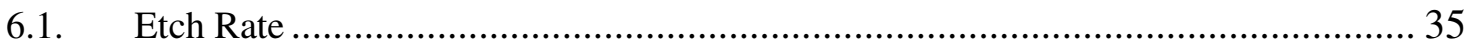

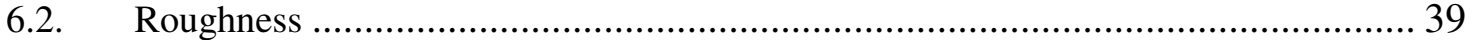

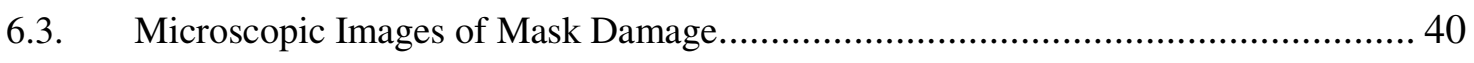

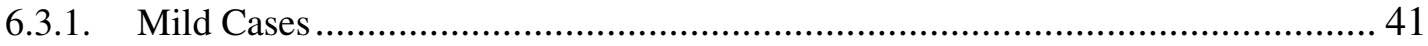

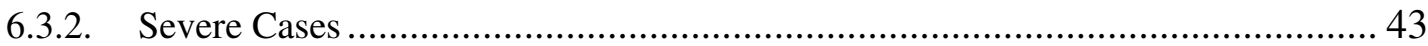

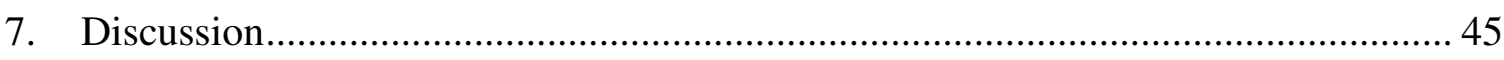

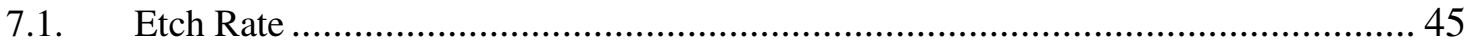

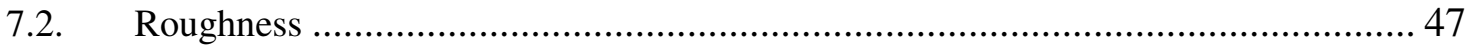

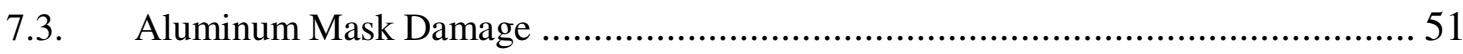

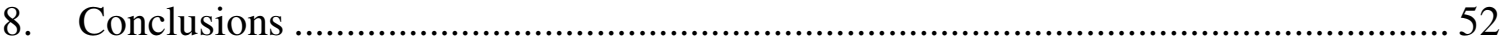

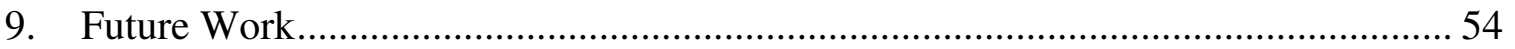

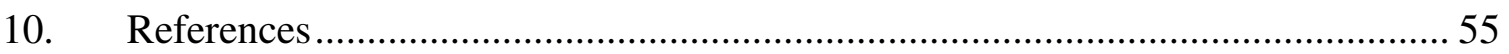




\section{List of Tables}

Table I: Composition of Corning 7740 Pyrex Glass.................................................... 16

Table II: Settings for Profilometer Scan ......................................................................... 32

Table III: Descriptive Statistics of Etch Rate ( $\mathrm{nm} / \mathrm{min}$ ) with Varying Partial Pressure

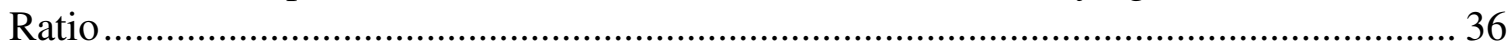

Table IV: Descriptive Statistics of Etch Rate with Varying RF Power............................ 36

Table V: ANOVA Output for Etch Rate..................................................................... 37

Table VI: Results from Tukey Pair-wise Comparison for Etch Rate ................................ 38

Table VII: Descriptive Statistics of Roughness with Varying Partial Pressure Ratio ...... 39

Table VIII: Descriptive Statistics of Roughness with Varying RF Power ........................ 39

Table IX: ANOVA Output for Roughness ………………………………………..... 40 


\section{List of Figures}

Figure 1: Undercutting in etch process can be measured by lateral etch distance per side. 6 Figure 2: Difference between positive and negative photoresist. Areas exposed to light becomes soluble for positive resist, and insoluble for negative resist.

Figure 3: Schematic detailing the structure of a DC plasma in the chamber. Electrons flow toward the anode and ions are attracted to the cathode [10].

Figure 4: Classification of different dry etching machines [16]

Figure 5: Structure of crystalline $\mathrm{SiO}_{2}$ (left) vs amorphous $\mathrm{SiO}_{2}$ (right). There is short range order, but no long range order in the amorphous structure [17].

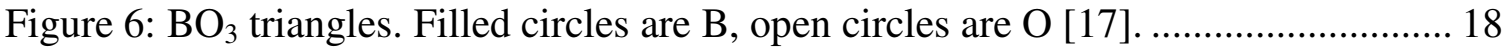

Figure 7: Table acquired from literature showing etch rate of different glasses [25]...... 21

Figure 8: XPS data of Borofloat glass etched in $\mathrm{CF}_{4}$ plasma at $350 \mathrm{~W}$ power

100 mTorr pressure, and $90 \mathrm{G}$ magnetic field [19]

Figure 9: Schematic detailing fabrication steps prior to dry etching............................ 27

Figure 10: Lithography mask used for patterning. Serpentines vary in width and length.28

Figure 11: RIE machine used to etch glass............................................................... 29

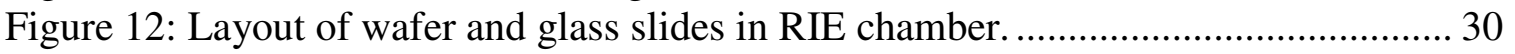

Figure 13: Schematic detailing factors and levels for DOE. ....................................... 31

Figure 14: Measurement of etch rate by averaging the etch depths of the channel......... 32

Figure 15: Application of a band pass filter on data to separate waviness and roughness.

Top: Raw data with filtered data. Bottom: Filtered data only with red representing

'roughness' and green representing 'waviness.' ....................................................... 34

Figure 16: Microscopic image of aluminum mask damage on etched glass wafer. 50:50

partial pressure ratio, RF power $300 \mathrm{~W}$.

Figure 17: Damage on mask present in three runs on one wafer. Top to bottom: Partial

pressure ratio 20:80/300 W, 20:80/100 W, 80:20/100 W.

Figure 18: Damage on aluminum mask. 50:50 partial pressure ratio, RF power $300 \mathrm{~W} .43$

Figure 19: Severe damage on aluminum mask. 20:80 partial pressure ratio, RF power 300 .

Figure 20: Damage on aluminum mask. 50:50 partial pressure ratio, $200 \mathrm{~W}$ RF power. 44 Figure 21: SEM images of Corning 7740 surfaces etched in $\mathrm{SF}_{6}$ plasmas at varying substrate bias powers [30].

Figure 22: XPS spectra of $\mathrm{B}_{1 \mathrm{~s}}, \mathrm{Al}_{2 \mathrm{p}}$, and $\mathrm{Na}_{1 \mathrm{~s}}$ from Corning 7740 glass etched in $\mathrm{SF}_{6}$ at varying substrate bias powers [30]. 


\section{Introduction}

\subsection{Microfluidics}

The ability to work with small amounts of fluids in a small area has been an emerging technology. This technology can have a large impact in chemistry, biology, physics, and the public as a whole. Microfluidics is defined as the science of analyzing or manipulating small amounts of fluids using channels that are only tens to hundreds of micrometers wide [1]. The fabrication of these microelectromechanical system (MEMS) devices requires extensive lithography and micromachining.

\subsection{Broader Impacts}

The use of microfluidic devices can have a large impact on society. The benefits from microfluidics are applicable to different fields. These devices can be utilized in "lab-on-a -chip" technology, condensing the amount of space required.

In medicine, clinical diagnostics is important in the prevention of disease. Miniaturizing the device leads to a smaller sample environment, decreased analysis time, and reduced chemical consumption. A smaller sample would mean less invasive collections. It also shortens the time required for the test, as a miniscule amount of fluid is needed to react. The reduction in chemical consumption reduces costs and waste dramatically [2]. 
Another advantage to miniaturization is the ability to make disposable devices. Sterility can be maintained in microfluidics used for clinical diagnostics. Ahn et al. were able to fabricate a disposable biochip that measured partial oxygen concentration, glucose, and lactate levels in blood using an integrated biosensor array. They also developed a handheld analyzer that could detect signals from the biochip [3].

The increase in fossil fuel use for the past couple centuries has led to concern about air quality. Lab-on-a-chip technology can monitor environmental pollutants. Takabayashi et al. developed a microchip fabricated from quartz glass, which detected nitrogen dioxide $\left(\mathrm{NO}_{2}\right)$ in the air. The microchip was designed to absorb gas, undergo the necessary chemical reaction, and detect $\mathrm{NO}_{2}$ by fluorescence. The development of this microchip gave the user portability that was not possible before with traditional automated devices. This technology made it easier for on-site monitoring [4].

The results of this thesis will also benefit other theses in the Cal Poly community. One student is researching the feasibility of anodically bonding a silicon wafer to glass. An optimal etch process can help him build a successful microfluidic chip. A number of students are researching quantum dots. Perhaps in the future, reactions conducted on the macroscale can be miniaturized and conducted on the microscale. 


\subsection{Materials Used}

Microfluidics is typically made of plastics. Glass and silicon were considered, but those materials were expensive, difficult to manufacture, and inappropriate for the analysis of biological samples. Opaque silicon made it difficult for optical methods of detection.

Thus, plastics like polydimethylsiloxane (PDMS) are currently used to fabricate microfluidics. PDMS is optically clear, chemically inert, permeable to gases, and its ease of manipulation makes it a perfect candidate for channels with micron-sized features $[5,6,7]$. PDMS is also biocompatible and nontoxic as it is used as a biomaterial in membranes and ear/nose implants [8]. To manufacture the microfluidic channels, SU-8 photoresist is spun onto a silicon wafer, exposed, and developed. This thick photoresist acts as the mold for the PDMS. PDMS is poured onto the mold, allowed to cure, and then peeled off. Hence, the pattern in the SU-8 is transferred into the PDMS.

Although the advantages of using PDMS are numerous, there are some limitations. The largest drawback to PDMS is its tendency to swell when it comes in contact with organic solvents. These include hexanes, ethyl ether, toluene, dichloromethane, acetone, and acetonitrile [9]. The swelling makes it difficult, if not impossible for organic solvents to flow through the channel. Glass offers the advantage of not reacting with these solvents. PDMS is also hydrophobic, which can hinder the wetting of the channel walls by aqueous solutions. With exposure to plasma oxidation, PDMS can be made hydrophilic due to the presence of silanol groups [5]. Glass is inherently hydrophilic, making it advantageous 
when analyzing aqueous samples. The hydrophilic nature of the material makes it easier for liquids to flow through the channel. 


\section{Technical Background}

\subsection{General Overview}

The purpose of this thesis is to characterize and optimize the process parameters for dry etching of Corning 7740 borosilicate glass. Specifically, the effect of partial pressure gas ratio and RF power on the etch rate and surface roughness will be studied. Etching is a common process used in semiconductor and MEMS (Micro-Electronic Materials Systems)-related applications. After a pattern is transferred onto the surface through photolithography techniques, the material is selectively removed via chemical and/or physical means. Two types of etching are currently in use: wet, through the use of a basic solution and dry, through the use of a plasma. Each has its own advantages and disadvantages.

\subsection{Etch Terminology}

There are several important etch terms that need to be defined before progressing further. The first is etch rate. Etch rate is defined as the thickness of material removed per unit time it is exposed to the etchant. The thickness removed is determined by surface profilometry and the time is measured using a timer. The etch rate is then computed from those measured quantities. In a manufacturing environment, a high etch rate is desired. However, if the etch rate is too high, the process may become out of control. 
The second is selectivity. Selectivity results from the fact that an etchant has a chemical preference to etch one material over another. It is the ratio of etch rates between different materials. For example, if the selectivity is $20: 1$ for polysilicon over oxide, it implies that polysilicon etches 20 times faster than the oxide. Selectivity is important as it helps the user choose the appropriate mask material for etching. If the mask etched faster than the exposed material, then the pattern would disappear and there would be no reason to use a mask at all.

The third is undercut. Undercut develops when etching occurs in the lateral direction. It is usually present in isotropic etches (equal etch rate in all directions). Undercut can be measured by the lateral etch distance per side (Figure 1).

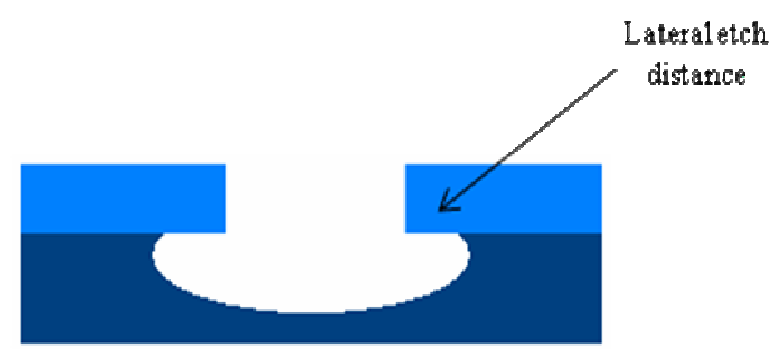

Figure 1: Undercutting in etch process can be measured by lateral etch distance per side.

Another way that undercut can be measured is by measuring the etch rate anisotropy, which can be defined by the following formula: 


$$
A=1-\left(R_{L} / R_{V}\right)
$$

where $R_{L}$ and $R_{v}$ are the lateral and vertical etch rates, respectively [10].

An isotropic etch typically results in rounded sidewalls, while an anisotropic etch results in vertical sidewalls.

The last important result of etching is the roughness of the etched surface. Roughness is an important metric as it can affect the functionality of the final device. It is measured using surface profilometry. Surface profilometry is useful as it provides quantitative data rather than qualitative. A diamond-tipped stylus with a radius of $2 \mu \mathrm{m}$ traverses the surface at a constant speed. The scan length and force can be set by the user. When the surface is being scanned, a transducer produces an electrical signal that is proportional to the stylus displacement. After amplification, the signal is sent to a chart recorder, which shows a magnified view of the original profile [11]. Multiple equations are used to characterize roughness, but the two most common are the $R_{\mathrm{a}}$, or center-line average (CLA) value and the $R_{\mathrm{q}}$, or root mean square (RMS) value. The CLA value is defined by the following equation:

$$
R_{a}=\frac{1}{L} \int_{0}^{L}|z| \cdot d x,
$$

where $\mathrm{L}$ is the scan length and $\mathrm{z}$ is the height of the surface measured above the mean level [11]. 
The CLA value does carry a limitation in that it is unable to differentiate between a spiky surface and a rounded surface. The RMS value alleviates this problem since it is more sensitive to high and low peaks and emphasizes higher peaks [12]. This is shown in the square term of the equation:

$$
R_{q}=\sqrt{\frac{1}{L} \int_{0}^{L} z^{2} d x}
$$

where $\mathrm{L}$ is the scan length and $\mathrm{z}$ is the height of the surface measured above the mean level [11].

Because of this advantage, roughness was quantified using RMS.

\subsection{Wet Etching Basics}

In wet etching, the wafer is placed in a basic solution that reacts with the exposed film to form soluble by-products. The substrate to be etched is first coated with photoresist, a compound that becomes insoluble/soluble when exposed to light. Its solubility to light is dependent on whether it is positive or negative photoresist (Figure 2). 


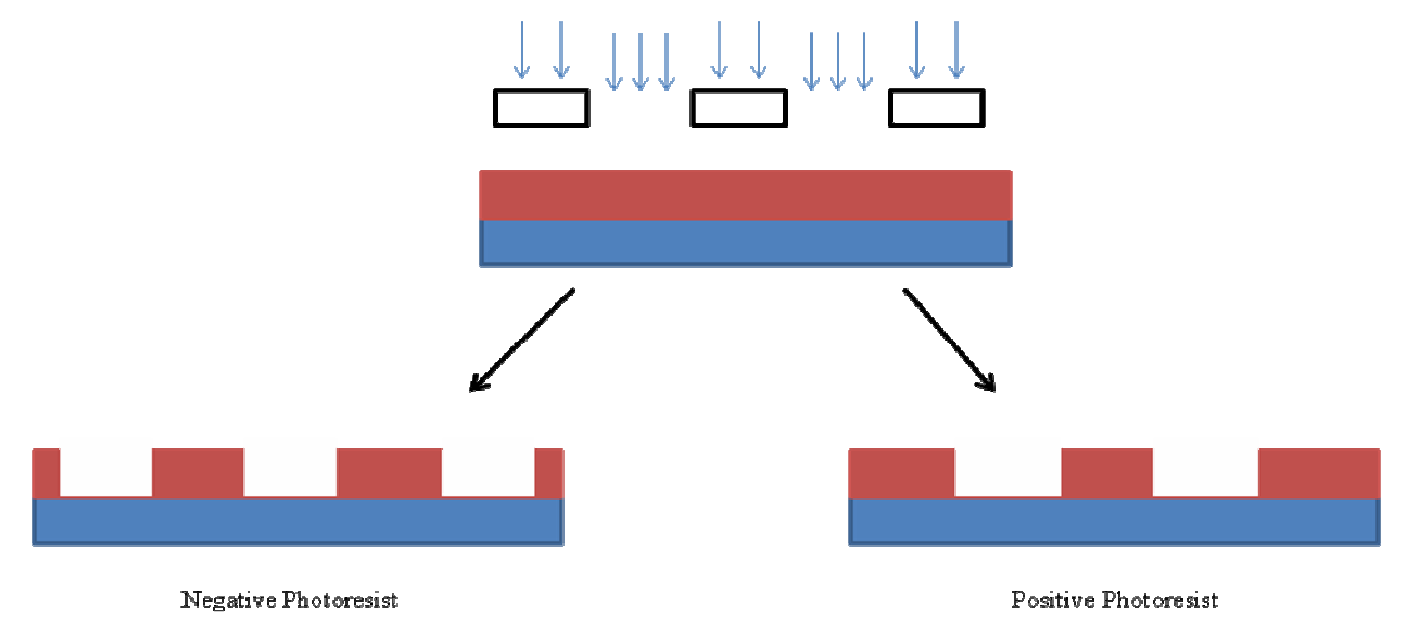

Figure 2: Difference between positive and negative photoresist. Areas exposed to light becomes soluble for positive resist, and insoluble for negative resist.

After aligning and exposure, the wafer is developed to reveal a pattern. If the photoresist is positive, areas exposed to light are removed. If it is negative, areas not exposed to light are removed. After developing, the photoresist is hard-baked to cross-link it and harden it for further processing. The photoresist can act as a mask for the etching, separating areas of the wafer to be etched. Typically, further processing such as PVD (Physical Vapor Deposition) or PECVD (Plasma-Enhanced Chemical Vapor Deposition) is used to deposit material, which would act as the etching mask. Wet etching is a chemical process that is highly selective, but is also isotropic and difficult to control. Particle contamination is also a concern, which limits this process to features larger than $2 \mu \mathrm{m}$ [10]. 


\subsection{Dry Etching}

Dry etching is advantageous in that the etch is more anisotropic and can be used for small feature sizes. The process is also easier to control and it eliminates the use and disposal of dangerous acids/chemicals used in wet etching.

\subsubsection{Physics and Chemistry of Dry Etching}

A plasma is generated and then used to etch the material. A molecular-gas is converted into an RF glow discharge, producing chemically-reactive species (free fluorine radicals). The chemically-reactive species diffuse to the surface of the material and are then adsorbed onto the surface to be etched. A chemical reaction occurs between the species and surface to be etched and a volatile by-product forms. The by-product desorbs from the surface and then diffuses into the bulk of the gas, which leaves the chamber. If any of these steps do not occur, then etching stops. Thus, the etch rate is dependent upon the slowest step in the process. Ionic-bombardment of the surface assists in the removal of material as well. This ionic-bombardment acts as a physical means for etching and provides dimensional selectivity, resulting in an anisotropic etch.

\subsection{Generation of a Glow Discharge}

The glow discharge is used for ionic-bombardment purposes and to create reactivespecies for the chemical reaction in etching. Molecular gases are chosen because they can 
be broken up into reactive species. For example, if $\mathrm{CF}_{4}$ is used, it can dissociate into $\mathrm{F}$, $\mathrm{CF}_{3}$, and $\mathrm{CF}_{3}^{+}$. Typical gases used in dry etching are $\mathrm{CF}_{4}, \mathrm{SF}_{6}, \mathrm{O}_{2}, \mathrm{Cl}_{2}, \mathrm{BCl}_{3}, \mathrm{Br}_{2}, \mathrm{CCl}_{4}$, Ar, $\mathrm{NF}_{3}, \mathrm{H}_{2}, \mathrm{C}_{3} \mathrm{~F}_{8}, \mathrm{CHF}_{3}$, and other molecular species. These gases are typically paired in optimal ratios and used as an etch recipe. The gas used is dependent upon the material being etched [10].

The glow discharge is the light generated from the plasma, a partially ionized gas. It contains approximately equal concentrations of positive (positive ions) and negative particles (electrons and negative ions). There are different processes that occur in the glow discharge. Assuming that the inlet gas is $\mathrm{AB}$, the processes that can occur in the glow discharge are as follows:

$$
\begin{array}{ll}
\text { Dissociation } & \mathrm{e}^{*}+\mathrm{AB} \leftrightarrow \mathrm{A}+\mathrm{B}+\mathrm{e} \\
\text { Atomic Ionization } & \mathrm{e}^{*}+\mathrm{A} \leftrightarrow \mathrm{A}^{+}+\mathrm{e}+\mathrm{e} \\
\text { Molecular Ionization } & \mathrm{e}^{*}+\mathrm{AB} \leftrightarrow \mathrm{AB}^{+}+\mathrm{e}+\mathrm{e} \\
\text { Atomic Excitation } & \mathrm{e}^{*}+\mathrm{A} \leftrightarrow \mathrm{A}^{*}+\mathrm{e} \\
\text { Molecular Excitation } & \mathrm{e}^{*}+\mathrm{AB} \leftrightarrow \mathrm{AB}^{*}+\mathrm{e}
\end{array}
$$

Where the superscript "*” refers to a metastable excited state [10]. The dissociated atoms or molecular fragments are known as radicals. Radicals are very reactive because of incomplete bonding. There is generally a higher concentration of radicals than ions in plasmas because they are generated at a faster rate and survive longer than ions. In order of decreasing concentration, the contents of the gas in an etch-chamber during the etching 
process are etch-gas molecules (70-98\%), etch-product molecules (2-20\%), radicals (0.1$20 \%)$, and charged species like positive ions, electrons, and negative ions (0.001-0.01\%) [13].

In a typical plasma reactor, two parallel plates are in a vacuum and connected to a DC power supply. A high voltage source is connected and an electric field is generated, causing the gas molecules to break down and become ionized. A large number of electrons and ions flow in the chamber, with the electrons attracted to the positively charged anode and the ions attracted to the negatively charged cathode (Figure 3).

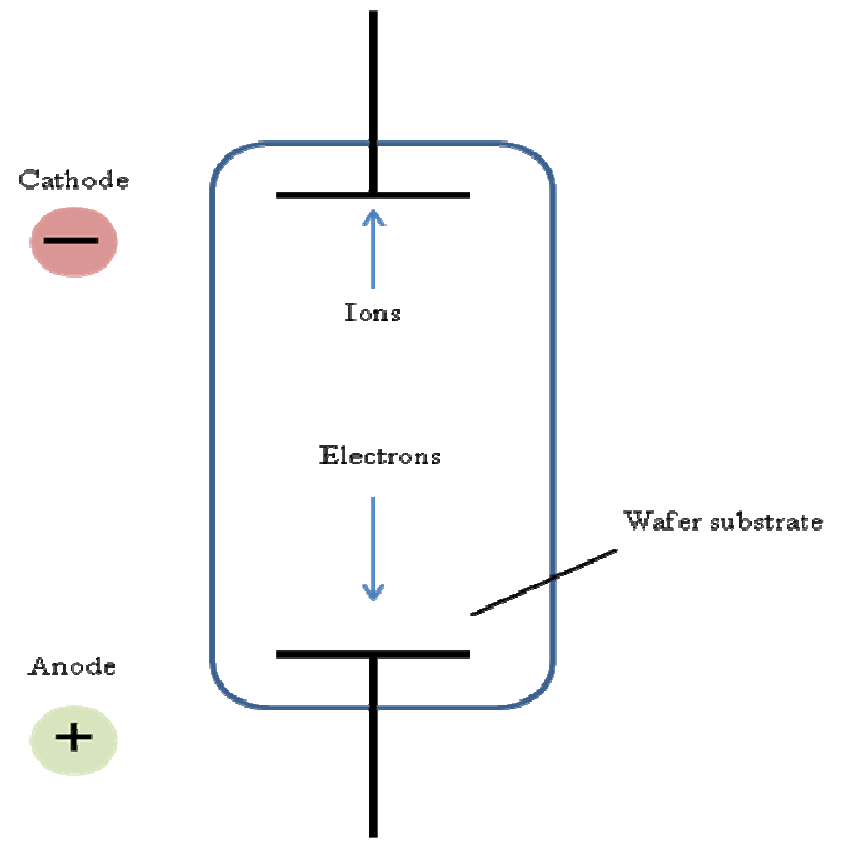

Figure 3: Schematic detailing the structure of a DC plasma in a PVD chamber. Electrons flow toward the anode and ions are attracted to the cathode [10].

As the electrons are attracted to the positively-charged anode where the wafer sits, the charge comes to an equilibrium so there is no electric field. Without an electric field, the plasma disappears. Because of this, the RIE system uses a RF glow discharge rather than 
a DC glow discharge. The alternating current prevents the electrode surface from reaching an equilibrium and allows electrons to oscillate back and forth. At a high frequency, electrons are rapidly accelerated while ions fall behind as they are too heavy. During each half cycle, electrons strike the surface of each electrode. In this way, the plasma is sustained in the reactor [10].

\subsection{Chemical Reactions}

The chemical reactions related to the dry etching of glass is similar to that of the dry etching of silicon. Etching is accomplished by the radical species created by the dissociation of fluorinated molecules, such as $\mathrm{SF}_{6}$. The fluorine atoms participate in the chemical reaction. The fluorine atoms attach to the silicon and continue to bond to it until $\mathrm{SiF}_{4}$ is formed. The volatile $\mathrm{SiF}_{4}$ desorbs from the surface as no more bonds can form with the silicon [14]. These chemical reactions create an isotropic etch, similar to wet etching. The addition of oxygen $\left(\mathrm{O}_{2}\right)$ to the plasma can increase the etch rate as the oxygen binds with the sulfur-fluorine radical, removing some of it from the plasma.

$$
\mathrm{SF}_{\mathrm{n}}+\mathrm{O} \rightarrow \mathrm{SOF}_{\mathrm{n}-1}+\mathrm{F}^{*}
$$

This increases the concentration of $\mathrm{F}$ atoms. However, at higher levels of $\mathrm{O}_{2}$, the plasma becomes diluted and the etch rate drops [15]. 
As mentioned before, the bombardment of ions, which is the physical component of etching, leads to a more anisotropic and directional etch. Another method is the build-up of non-volatile species on the sidewalls. The non-volatile species deposited on the surface of the wafer can only be removed by physical means. Because the ions are directed by the electric field inside the chamber, they are limited to a vertical direction. Thus, nonvolatile species build up on the sidewalls, protecting it from lateral etching [10].

\subsubsection{Dry Etching Technology}

There are different dry etching machines that are currently used. Each has a different configuration and methods for generating ions. Figure 4 shows the six different machines.

\begin{tabular}{|c|c|c|c|c|c|}
\hline & $\begin{array}{l}\text { ions generated } \\
\text { by }\end{array}$ & $\begin{array}{c}\text { ions extracted } \\
\text { by }\end{array}$ & $\begin{array}{l}\text { gas selected } \\
\text { to be }\end{array}$ & $\begin{array}{l}\text { usual } \\
\text { name }\end{array}$ & $\begin{array}{c}\text { diagram and } \\
\text { distinguishing features }\end{array}$ \\
\hline \multirow{2}{*}{ (a) } & $\begin{array}{l}\text { hot wire } \\
\text { (DC) }\end{array}$ & DC fields & not reactive & $\begin{array}{l}\text { ion beam etching } \\
\text { (IBE) }\end{array}$ & $\begin{array}{l}\text { noble gas } \\
\text { ion beam }\end{array}$ \\
\hline & $\begin{array}{l}\text { hot wire } \\
\text { (DC) }\end{array}$ & DC fields & reactive & $\begin{array}{l}\text { chemically assisted } \\
\text { ion beam etching } \\
\text { (CAIBE) }\end{array}$ & \\
\hline (b) & RF discharge & same RF field & reactive & $\begin{array}{l}\text { reactive-ion etching } \\
\text { (RIE) }\end{array}$ & $\begin{array}{c}<50 \mathrm{mT} \text { pressure, } \\
\text { driven electrode smaller }\end{array}$ \\
\hline \multirow[b]{2}{*}{ (c) } & RF discharge & same RF field & not reactive & magnetron sputtering & \multirow[b]{2}{*}{$\begin{array}{l}\text { axial magnetic field } \\
\text { to increase ion density }\end{array}$} \\
\hline & RF discharge & same RF field & reactive & magnetron reative & \\
\hline \multirow[b]{2}{*}{ (d) } & microwave field & separate RF & reactive & electron-cyclotron- & $\mu \mathrm{W}$ wave power \\
\hline & $\begin{array}{l}\text { with magnetic } \\
\text { field }\end{array}$ & field & & $\begin{array}{l}\text { resonance- } \\
\text { reactive-ion etching } \\
\text { (ECR-RIE) }\end{array}$ & $\begin{array}{cc}\text { ECR increases } \\
\text { ion density }\end{array}$ \\
\hline (e) & $\begin{array}{l}\text { RF field induced by } \\
\text { a driven loop }\end{array}$ & $\begin{array}{l}\text { separate RF } \\
\text { or LF field }\end{array}$ & reactive & $\begin{array}{l}\text { inductively coupled } \\
\text { plasma etching } \\
\text { (ICPE) }\end{array}$ & 8 8 coil carrying RF \\
\hline$(f)$ & RF discharge & same RF field & reactive & $\begin{array}{l}\text { plasma etching } \\
\text { (PE) }\end{array}$ & $\begin{array}{l}\text { relatively high pressure } \\
\text { around } 1 \mathrm{mT}\end{array}$ \\
\hline
\end{tabular}

Figure 4: Classification of different dry etching machines [16]. 
In a RIE, the two electrodes are usually different sizes. The sample to be etched is placed on the smaller electrode and it is driven by the radio-frequency (RF) field. The larger electrode is grounded. The self-bias voltage is developed across the dark space and allows ions to accelerate towards the sample. The proportion of gas molecules that are ionized is small. This proportion can be increased by increasing the RF power or bias voltage.

For magnetron sputtering, a magnetic field is applied to the machine. This allows the electrons to spiral, increasing the time they are free to ionize the gas. The consequences of the magnetic field is a heavily ionized plasma, which increases the etch rate.

In electron-cyclotron-resonance-reactive-ion etching (ECR-RIE), the plasma is generated by a microwave field and extracted by a separate RF field. A magnetic field is applied axially; this improves the efficiency of the ionization of the gas and thus leads to a denser plasma.

Another common dry etching machine is inductively coupled plasma etching (ICP). A RF coil wrapped around the chamber inductively couples the RF power. Ions are extracted from another source [16]. 


\subsection{Materials: Glass Structure and Composition}

The material that was etched was Pyrex ${ }^{\circledR}$ Code 7740 glass. It is composed of the following (Table I):

Table I: Composition of Corning 7740 Pyrex Glass

\begin{tabular}{|c|c|}
\hline \multicolumn{2}{|c|}{ Composition (\%) } \\
\hline $\mathrm{SiO}_{2}$ & 80.6 \\
\hline $\mathrm{B}_{2} \mathrm{O}_{3}$ & 13.0 \\
\hline $\mathrm{Na}_{2} \mathrm{O}$ & 4.0 \\
\hline $\mathrm{Al}_{2} \mathrm{O}_{3}$ & 2.3 \\
\hline Miscellaneous Traces & 0.1 \\
\hline
\end{tabular}

Glasses are formed by cooling a molten ceramic structure so rapidly, that it is difficult for atoms to order themselves. Because there is not enough time for the atoms to arrange themselves in a crystalline order, the resulting solid is amorphous. The amorphous solid is characterized by short-range order, but it lacks long-range order (Figure 5) [17]. 

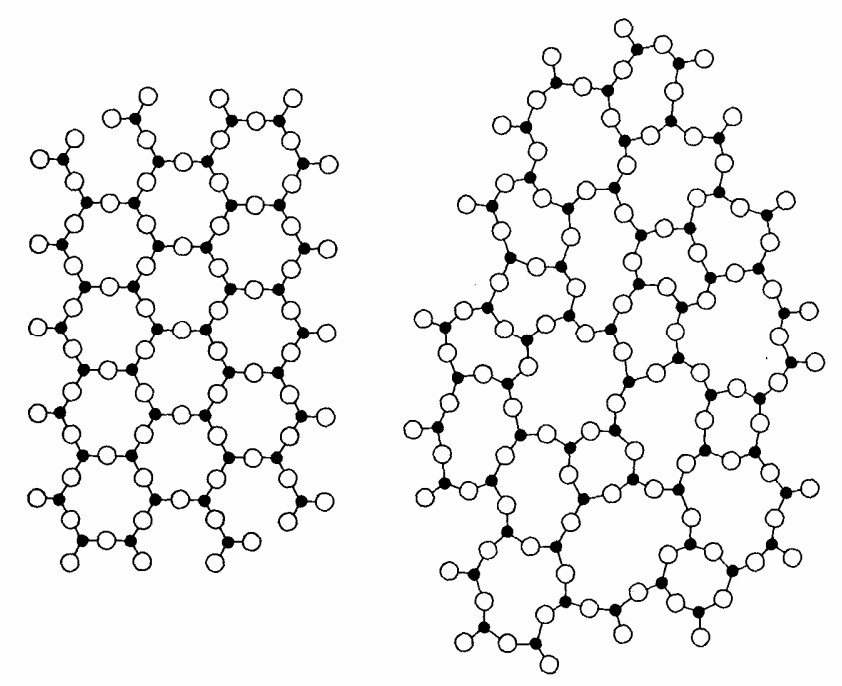

Figure 5: Structure of crystalline $\mathrm{SiO}_{2}$ (left) vs amorphous $\mathrm{SiO}_{2}$ (right). There is short range order, but no long range order in the amorphous structure [17].

The silicon is bonded to oxygen in a tetrahedron structure. The lack of long-range order in glasses is from the variation in the silicon-silicon distances. Mozzi and Warren proposed that $\mathrm{B}_{2} \mathrm{O}_{3}$, the second highest component of borosilicate glass, was found to consist of $\mathrm{BO}_{3}$ triangles. They are linked together in a boroxyl configuration. Adding alkali or alkaline earth oxides to $\mathrm{SiO}_{2}$ breaks up the 3-D network as they are ionically bonded to the oxygen atoms, creating singly bonded oxygen atoms. This then decreases the bond strength of the material and increases the ratio of oxygen to silicon atoms. In borate glasses, the addition of alkali or alkaline earth oxides to $\mathrm{B}_{2} \mathrm{O}_{3}$ causes the formation of $\mathrm{BO}_{4}$ tetrahedra [18]. 


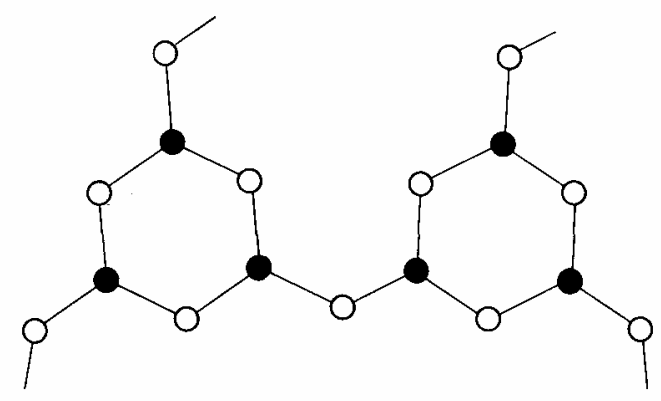

Figure 6: $\mathrm{BO}_{3}$ triangles. Filled circles are $\mathrm{B}$, open circles are $\mathrm{O}$ [17].

Up to a certain point (30 mole \% alkali oxide), the fraction of boron atoms in a tetrahedral coordination levels off, indicating an increase of singly bonded oxygens [17]. The amorphous nature of glass allows a faster etch rate due to the fact that bonds are stretched and in a weaker state. It is easier for the atoms to be removed from the substrate. 


\section{Previous Work}

\subsection{Literature Review}

A number of studies have been conducted on the dry etching of borosilicate glass, or other types of glasses.

\subsubsection{Dry Etching Equipment}

Much of the literature cited used RIE to etch the glass. Metwalli and Pantano used magnetically enhanced reactive ion etching (MERIE) to study the etching behavior of phosphate and silicate glasses in both fluorocarbon and Ar plasmas. They made sure to purge the chamber with Ar before and after each run to prevent contamination of the chamber [19]. Park et al. and Akashi and Yoshimura both used deep reactive ion etching (DRIE) in an inductively-coupled plasma in their experiments. Both were connected to a turbo-molecular pump (TMP) and held at a constant temperature using chillers [20, 21].

\subsubsection{Mask Materials}

Typical mask materials were anodically-bonded silicon, metals such as aluminum, nickel, or chrome, and photoresist. Akashi and Yoshimura fabricated a silicon mask by dry etching holes and removing the substrate through backside etching. The silicon was then 
anodically bonded to the glass [21]. Ronggui and Righini found that photoresist was not a suitable mask material. To avoid excessive heating, they etched for five minutes and rested for another five minutes. They found that the etch rate of the photoresist was much higher than that of the glass, which meant the selectivity was too low [22]. Baram and Naftali were aware of this and found that using a thick photoresist such as SU-8 could alleviate the problem [23]. Many found that metal masks could introduce contamination, and thus avoided it [24]. The contamination was caused by the production of $\mathrm{AlF}_{3}$, which is a non-volatile product that redeposited onto the surface and contaminated the mask.

\subsubsection{Gases Used}

The gases used for etching were typically a combination of a fluorine-containing gas and one to assist the etching process. Park et al. used a combination of $\mathrm{SF}_{6}$ and Ar to etch borosilicate glass. They found that with pure $\mathrm{SF}_{6}$, undercutting occurred below the $\mathrm{Ni}$ mask due to chemical etching. Adding Ar to the $\mathrm{SF}_{6}$ removed the undercut, but decreased the etch rate from 750 to $540 \mathrm{~nm} / \mathrm{min}$ [20]. Li et al. used a mixture of $\mathrm{SF}_{6} / \mathrm{Xe}$ and $\mathrm{SF}_{6} / \mathrm{Ar}$. They found that the average surface roughness $\left(R_{a}\right)$ after etching with $\mathrm{SF}_{6} / \mathrm{Xe}$ was smaller than after etching with only $\mathrm{SF}_{6}$. This was due to the contribution of the inert gas molecules $(\mathrm{Xe})$ to the physical sputtering effect. Contaminants were removed from the etched surface, which decreased the roughness [24]. 


\subsubsection{Glass Composition Effects}

A couple studies have been conducted on how composition of glasses affects the etch. Thiénot et al. studied the etch rates of nine different silica or glasses. They found that etch rate increased when the amount of volatile oxides increased (Figure 7) [25].

\begin{tabular}{|c|c|c|c|c|c|c|c|c|c|c|}
\hline \multirow[t]{2}{*}{ Glass $^{2}$} & \multirow[t]{2}{*}{ Etch rate $(\mathrm{nm} / \mathrm{min})$} & \multicolumn{9}{|c|}{ Chemical composition $(\% \text { weight })^{b}$} \\
\hline & & $\mathrm{SiO}_{2}$ & $\mathrm{~B}_{2} \mathrm{O}_{3}$ & $\mathrm{Al}_{2} \mathrm{O}_{3}$ & $\mathrm{ZnO}$ & $\mathrm{TiO}_{2}$ & $\mathrm{BaO}$ & $\mathrm{Na}_{2} \mathrm{O}$ & $\mathrm{K}_{2} \mathrm{O}$ & Others \\
\hline 7913 & $58.7 \pm 0.6$ & 96.4 & 3.0 & 0.5 & & & & & & 0.1 \\
\hline 7740 & $28.6 \pm 0.7$ & 80.6 & 13.0 & 2.3 & & & & 4.0 & & 0.1 \\
\hline BK7 & $7.17 \pm 0.09$ & 68 & 15 & & & & 6 & 6 & 5 & \\
\hline 0211 & $6.74 \pm 0.16$ & 64 & 9 & 3 & 7 & 3 & & 7 & 7 & \\
\hline D263 & $6.99 \pm 0.43$ & 64.1 & 8.4 & 4.2 & 5.9 & 4.0 & & 6.4 & 6.9 & 0.1 \\
\hline AF45 & $3.17 \pm 0.13$ & 49.6 & 14.2 & 11.4 & & & 24.1 & & & 0.7 \\
\hline
\end{tabular}

Figure 7: Table acquired from literature showing etch rate of different glasses [25].

At a higher $\mathrm{SiO}_{2}+\mathrm{B}_{2} \mathrm{O}_{3}$ content, the etch rate was higher. These oxides were considered volatile since both boiling points are below $0{ }^{\circ} \mathrm{C}[19,26]$. The other compounds were considered non-volatile and accumulated on the etched surface. They could only be removed by ion bombardment. Leech found that an increase in non-volatile oxides decreased the etch rate; the compositions were enough to reduce the reactive component of the plasma [26]. This was confirmed also by Metwalli and Pantano, who studied the dependence of composition when dry etching glass. Using X-ray photoelectron spectroscopy (XPS), they found that there was an increase in surface elemental concentrations of less-volatile fluoride species, and a decrease in highly-volatile fluoride species as etching time increased [19]. Figure 8 illustrates their findings. 


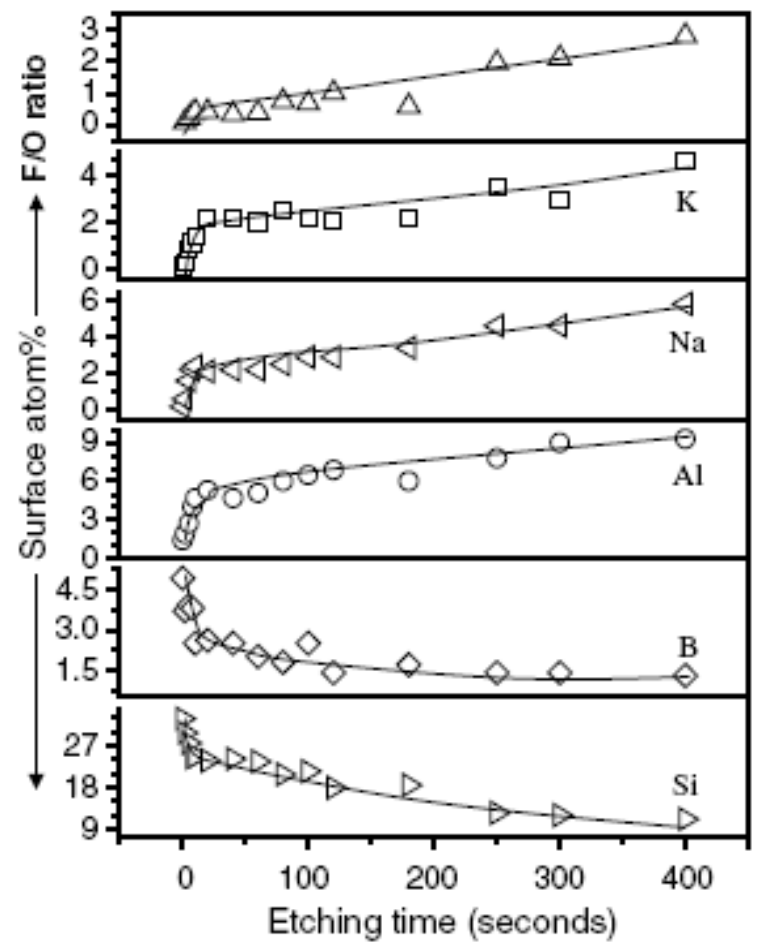

Figure 8: XPS data of Borofloat glass etched in $\mathrm{CF}_{4}$ plasma at $350 \mathrm{~W}$ power, $100 \mathrm{mTorr}$ pressure, and 90 G magnetic field [19].

There was a sharp increase in the non-volatile species $(\mathrm{K}, \mathrm{Na}, \mathrm{Al})$, followed by a more gradual increase, whereas the volatile species ( $\mathrm{B}$ and $\mathrm{Si}$ ) had a sharp decline and then leveled off.

\subsubsection{Variation in Power, Bias Voltage, and Pressure}

There were some studies on the effects of varying power, bias voltage, and pressure on the etch results. Akashi and Yoshimura found that as the gas pressure decreased, the etch rate increased. With a decrease in pressure, the mean fee path of ions increased, which 
meant more ionic bombardment occurred. They also determined that an increase in bias power and antenna power led to an increase in etch rate [21]. In Metwalli and Pantano's study on the etch rate of glasses at varying powers, it was determined that the etch rate of all the glasses increased linearly with increasing power [19]. Li et al. agreed that a decrease in pressure led to a higher etch rate. Furthermore, they found that a lower pressure led to a lower roughness. With a larger mean free path, physical sputtering was able to remove non-volatile products that accumulated on the surface. For bias voltage, they found that increasing it led to a lower roughness and higher etch rate. Increasing the bias voltage increased ion bombardment [27]. This could come at a cost - the mask can become damaged and the accuracy of the patterned features can be compromised [23]. Park et al. also found that increasing the bias voltage led to a higher etch rate. However, after surpassing a $V_{\mathrm{dc}}$ of $-500 \mathrm{~V}$, the etch rate decreased. They attributed this to the redeposition of $\mathrm{Ni}$ atoms from the etching mask.

\subsubsection{Aspect-Ratio-Dependent Etching}

An interesting result was observed in some of the studies. The etch rate gradually increased as the width of the channel increased. The etching rate declined as the aspect ratio increased. This phenomenon is called aspect-ratio-dependent-etching (ARDE). Akashi and Yoshimura experienced ARDE. Comparing $\mathrm{C}_{4} \mathrm{~F}_{8}$ and $\mathrm{CHF}_{3}$, they found that $\mathrm{CHF}_{3}$ caused more lateral etching. Both had an increase in etch depth. They attributed it to the fact that a polymer film could not be generated to protect the sidewalls in a narrower opening. The $\mathrm{C}_{4} \mathrm{~F}_{8}$ was able to generate a thicker polymer film, which gave a 
more directional etch [21]. Similar effects of ARDE were found in another study [23]. Li et al. found that a narrower opening gave a more directional etch due to the build-up of non-volatile products on the sidewall [27]. 


\section{Research Objectives}

The goal of this thesis is to characterize and optimize the process for the dry etching of borosilicate glass. Specifically, etch rate and RMS roughness will be studied, as these parameters are important in the success of manufacturing a microfluidic chip. The

findings from this thesis can benefit future theses as dry etching can be used to fabricate MEMS devices. 


\section{Materials and Methods}

\subsection{Fabrication and Processing}

Figure 9 illustrates the process steps for the dry etching of borosilicate glass. Six $100 \mathrm{~mm}$ Corning 7740 Pyrex ${ }^{\circledR}$ wafers were cleaned in a Piranha solution $\left(\mathrm{H}_{2} \mathrm{SO}_{4}+\mathrm{H}_{2} \mathrm{O}_{2}\right)$ at $70^{\circ} \mathrm{C}$ for 10 minutes. After they were cleaned, a thin layer of aluminum was deposited onto the wafers using physical vapor deposition (PVD); this acted as the etching mask. The wafers were then coated with Shipley 1813 positive photoresist and soft-baked for 60 seconds on a hot plate set at $90^{\circ} \mathrm{C}$. Using a Canon PLA-501FA aligner, the wafers were exposed with UV light for about nine seconds. The photoresist was developed with the Microposit CD$26(2.5 \%$ TMAH) developer at room temperature for two minutes with agitation. After a short post-develop inspection using an optical microscope, the wafers were hard-baked at $150^{\circ} \mathrm{C}$ for 60 seconds. To remove the aluminum, and therefore expose the glass channels, the wafers were wet etched in Transene Aluminum Etchant Type A for 30 seconds at $50^{\circ} \mathrm{C}$. The hard-baked photoresist was removed by soaking the wafers in the Microposit Remover 1165 for 15 minutes at $60^{\circ} \mathrm{C}$. After quenching in deionized water and drying with $\mathrm{N}_{2}$, the wafers were ready to be etched. 
Glass wafer

PVD

Aluminum

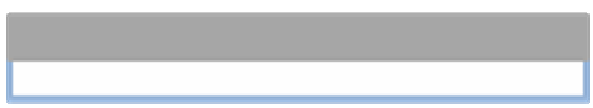

Spin coat

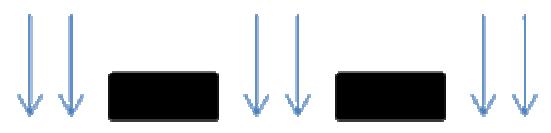

photoresist,

align, and

expose

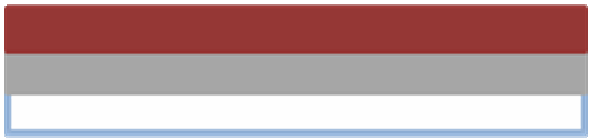

Develop

photoresist

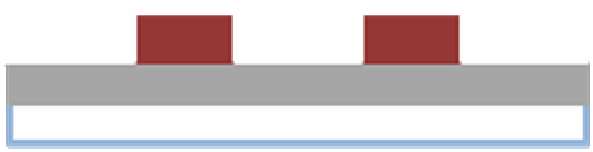

Wet etch

Aluminum

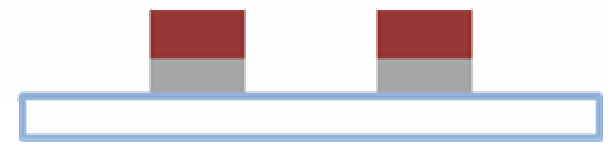

Resist strip

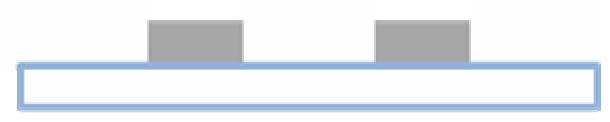

Figure 9: Schematic detailing fabrication steps prior to dry etching.

\subsection{Etching}

The pattern used on the exposure mask contained serpentine channels, which had widths of 50,100, and $200 \mu \mathrm{m}$, and lengths of 50, 100, and $200 \mathrm{~mm}$. There were nine total serpentines on the wafer, arranged in a $3 \times 3$ array (Figure 10). 


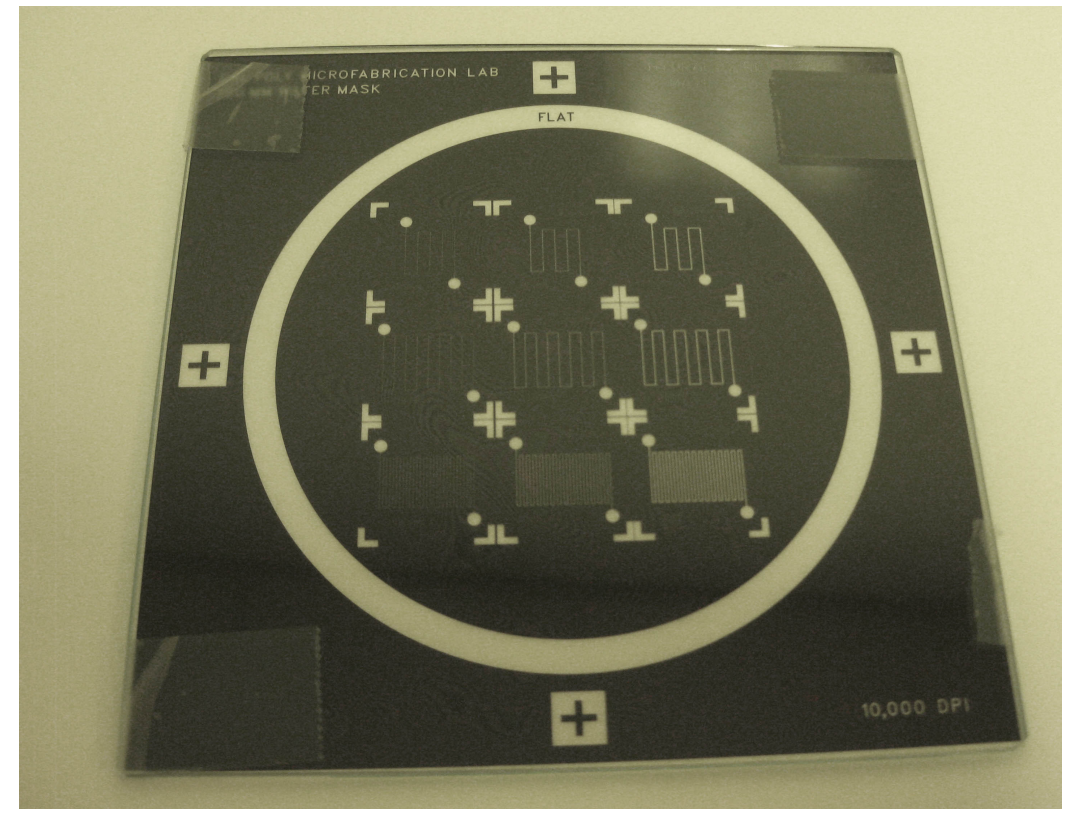

Figure 10: Lithography mask used for patterning. Serpentines vary in width and length.

The RIE machine is the AGS Plasma S17 (Figure 11). It is supplied with sulfur hexafluoride $\left(\mathrm{SF}_{6}\right)$ and oxygen $\left(\mathrm{O}_{2}\right)$. To operate the RIE machine, the chamber was pumped down to $30 \mathrm{mTorr}$. The gas flow valves were opened and the partial pressures were set as a ratio out of 150 mTorr. The RIE machine has an automatic pressure controller (Type 152 Automatic Pressure Controller) that converts the 150 mTorr in the chamber directly to the set pressure of the etching process, 300 mTorr. Ideally, the combined partial pressures should be half of the set pressure. After the partial pressures were set, a key was turned to allow the automatic pressure controller to take over the process. The RF power was turned on and the power was set. The recipe set procedure was important as it allowed the etching process to begin immediately after turning on the RF power, eliminating the need to adjust the parameters while a plasma was being emitted. 


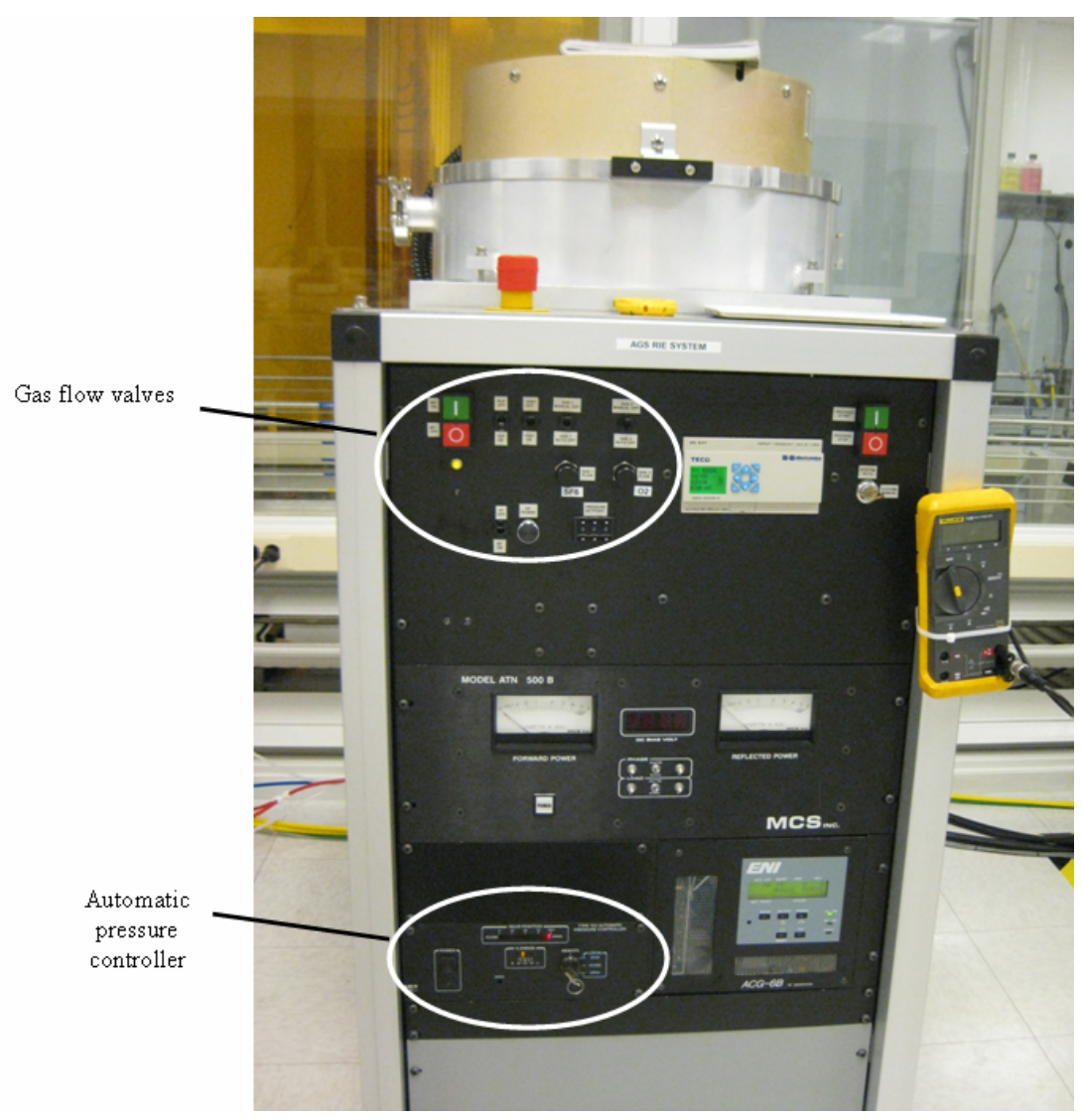

Figure 11: RIE machine used to etch glass.

After setting the recipe, the previous steps were followed in reverse to turn the machine off. The chamber was vented and the glass wafer was centered on the stage. Because the wafer could move during the pump down/venting procedures, it was held in place using glass slides as shown in Figure 12. The glass slides were also used to cover parts of the wafer so that multiple runs could be conducted on one wafer. After each run was completed, the chamber was pumped down, purged, and vented. The glass slides were moved to reveal a new surface for the next run. All etching processes were 20 minutes long. 


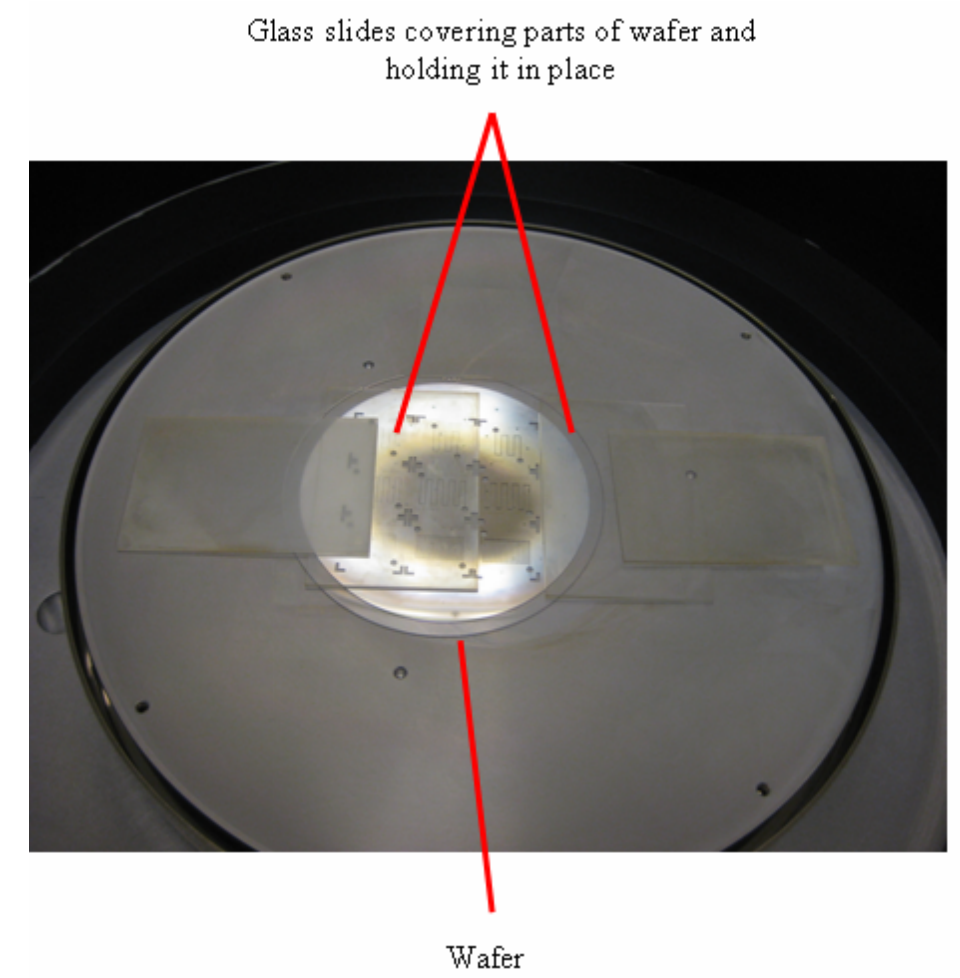

Figure 12: Layout of wafer and glass slides in RIE chamber.

\subsection{Design of Experiments (DOE)}

A design of experiments was implemented to ensure that the results were unbiased and all possible treatments were accounted for. There were two factors (power and gas ratio), with three levels each (Figure 13). The low, middle, and high levels of each factor were designated as ' 1 ,' '2,' and ' 3 ' respectively. For ratio, the low, middle and high values correlated with increasing $\mathrm{SF}_{6}$ content. 


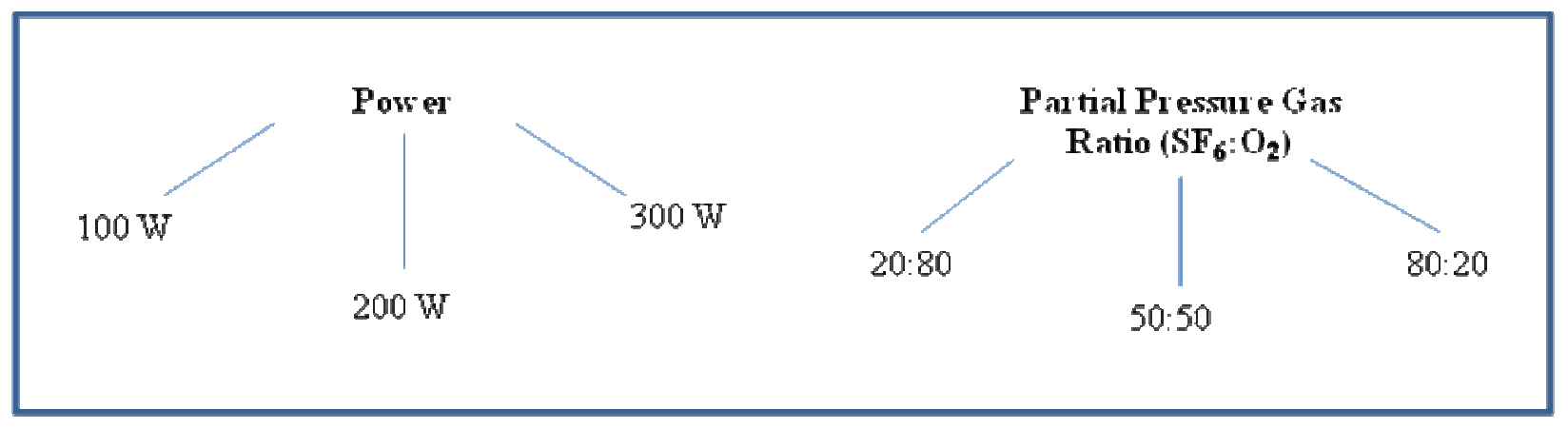

Figure 13: Schematic detailing factors and levels for DOE.

Two factors with three levels each indicate nine total treatments. Two repetitions were conducted, totaling 18 runs. With six wafers, three runs were conducted on each wafer. All the runs could not be represented on each wafer, so a partially balanced incomplete block design was used. The runs were randomized such that the same pair of treatments was not on any one wafer. Also, all treatments were represented the same number of times across the wafers.

\subsection{Data Collection}

Data was collected using a stylus profilometer. Before testing began, the settings were changed to the following: 
Table II: Settings for Profilometer Scan

\begin{tabular}{|c|c|}
\hline Speed $(\mathrm{mm} / \mathrm{s})$ & 0.05 \\
\hline Scan Length $(\mathrm{mm})$ & 1.00 \\
\hline Range $(\mu \mathrm{m})$ & 10.0 \\
\hline Force $(\mathrm{mg})$ & 10.0 \\
\hline Filter Level & 3 \\
\hline Data Points & 4670 \\
\hline
\end{tabular}

To determine the etch rate, the reference line was first placed at the mean line. The measurement line was placed in the etched channel. Because the etched surface had a varying amount of etch depths, the measurement line was resized to account for the different heights. By resizing the measurement line, all the heights were averaged into a single value (Figure 14). The height was divided by the etch time (20 minutes) to acquire an etch rate.

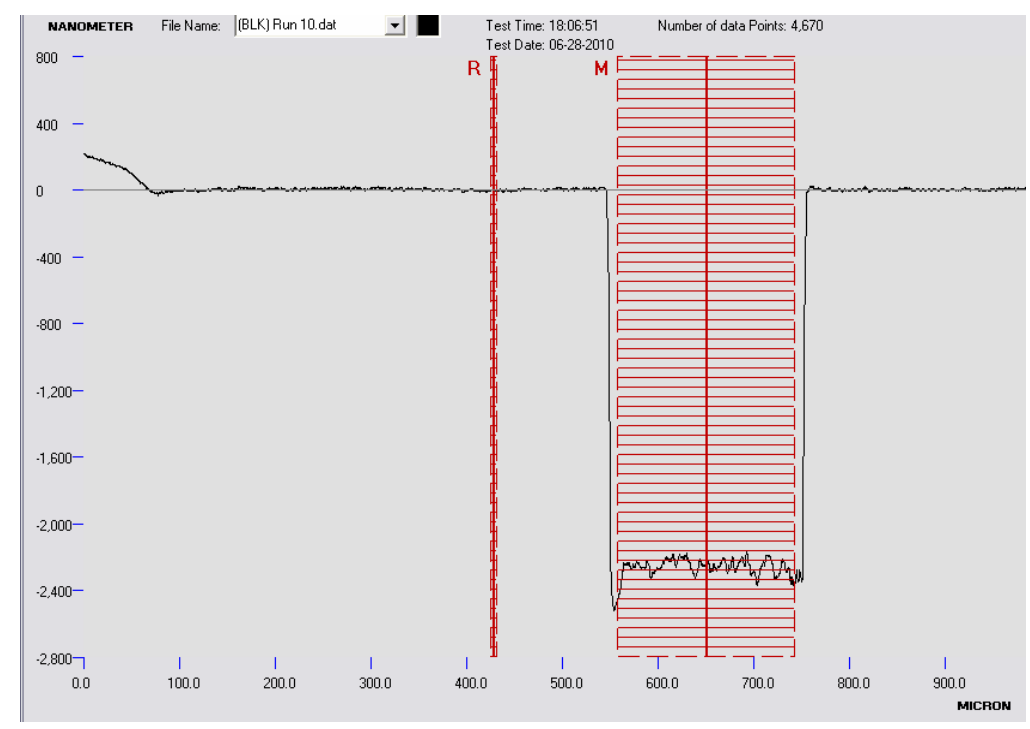

Figure 14: Measurement of etch rate by averaging the etch depths of the channel. 
To determine the roughness, both the reference and measurement lines were placed inside the channel. The roughness was calculated for the surface that was between those lines. Depending on where the lines were placed, the roughness would change (this can be seen from Equation 3). However, the differences were slight (2-3 nm), so one roughness measurement was taken for each run. In cases where the channel was at an incline, the software was able to level it to a 'Least Square' fit. If the surface was wavy, it could alter the roughness calculation. 'Waviness' is defined as a surface irregularity that has a large wavelength, or small frequency [12]. As stated before, roughness is being studied because smoothness is important in the functioning of microfluidics. The liquids that flow through a channel contain small particles that can become trapped in microtrenches. Since waviness is considered an irregularity that has a large wavelength, it was ruled out as a factor in the flow rate. Thus, it was necessary to separate the 'waviness' from the 'roughness' of the surface. To do this, a band pass filter was applied. A value was typed into the software program indicating what wavelengths would be considered 'wavy' vs. 'rough.' The value could also be generated by moving a bar until the desired value was found (Figure 15). The bar was moved until the 'waviness' image was similar to that shown in the original profile. 


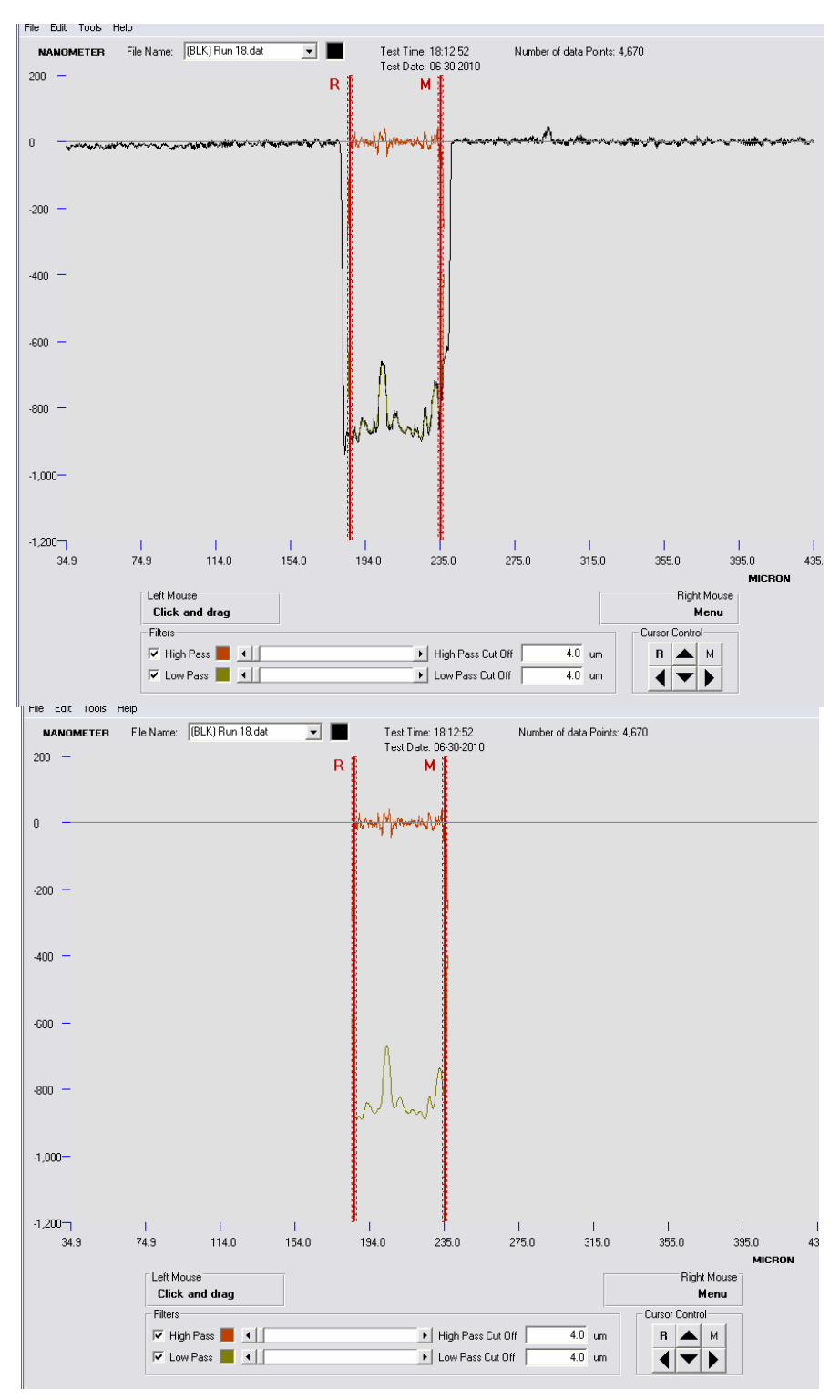

Figure 15: Application of a band pass filter on data to separate waviness and roughness. Top: Raw data with filtered data. Bottom: Filtered data only with red representing 'roughness' and green representing 'waviness.'

Of the 18 runs, there were two instances where applying a band pass filter was necessary. The chosen cut-off value was $4.0 \mu \mathrm{m}$ for both instances. 


\section{Results}

The sample means and standard deviations were calculated. Afterwards, an analysis of variance (ANOVA) test was conducted to test for statistical significance. The ANOVA test operates under the assumption that the residuals are normal and of equal variance. If they satisfy both conditions, then it is okay to proceed onto hypothesis testing. If it does not meet one of the conditions, then a power transformation is necessary to linearize the model. Once the residuals (or transformation) are considered normal and of equal variance, then the ANOVA output is analyzed to see if there is an interaction between

two factors. If the interaction is not significant, then it is removed from the model, and an ANOVA is run again with the interaction removed. A problem that occurred with this analysis procedure was that after removing the interaction from the model, the residuals of the new model would not be normal or have equal variance. Thus, several ANOVAs and their corresponding residuals were generated and the appropriate analysis was chosen.

\subsection{Etch Rate}

The sample means and standard deviations for etch rate with partial pressure ratio and RF power as factors were tabulated (Tables III and IV). 
Table III: Descriptive Statistics of Etch Rate (nm/min) with Varying Partial Pressure Ratio

\begin{tabular}{|c|c|c|c|}
\hline $\begin{array}{c}\text { Partial Pressure } \\
\text { Ratio }\end{array}$ & Sample Size (n) & Mean (nm/min) \pm & Standard Deviation \\
\hline 1 & 6 & S.E. & \\
\hline 2 & 6 & $96.5 \pm 20.8$ & 50.8 \\
\hline 3 & 6 & $124.5 \pm 18.2$ & 44.7 \\
\hline
\end{tabular}

Table IV: Descriptive Statistics of Etch Rate with Varying RF Power

\begin{tabular}{|c|c|c|c|}
\hline RF Power (Watts) & Sample Size (n) & Mean (nm/min) \pm & Standard Deviation \\
& & S.E. & \\
\hline 100 & 6 & $54.6 \pm 11.5$ & 28.3 \\
\hline 200 & 6 & $79.2 \pm 18.1$ & 44.4 \\
\hline 300 & 6 & $116.2 \pm 30.2$ & 74.0 \\
\hline
\end{tabular}

To determine whether the partial pressure ratio or RF power had an effect on the etch rate, an ANOVA test with $\alpha=0.05$ was generated. The null and alternate hypotheses were as follows:

For power, $H_{0}: \mu_{100}=\mu_{200}=\mu_{300}$

$H_{a}$ : At least two $\mu$ 's are different.

For partial pressure ratio, $H_{0}: \mu_{1}=\mu_{2}=\mu_{3}$

$H_{a}$ : At least two $\mu$ 's are different. 
The ANOVA test operates under the assumption that the residuals are normal and of equal variance. According to the residual plots, the data appeared normal and had equal variance.

The data points on the normal probability plot fell closely to the line, indicating normality. There was no particular pattern on the Residual vs. Fits graph, indicating constant variance. The ANOVA output is shown in Table V. Significant factors are shaded.

Table V: ANOVA Output for Etch Rate

\begin{tabular}{|c|c|c|c|c|c|c|}
\hline Source & DF & Seq SS & Adj SS & Adj MS & F & P \\
\hline Wafer & 5 & 17940.2 & 4221.9 & 844.4 & 3.4 & 0.129 \\
\hline Ratio & 2 & 19491.9 & 20244.8 & 10122.4 & 40.82 & 0.002 \\
\hline Power & 2 & 9697.5 & 9777.4 & 4888.7 & 19.71 & 0.008 \\
\hline Ratio*Power & 4 & 4622 & 4622 & 1155.5 & 4.66 & 0.083 \\
\hline Error & 4 & 992 & 992 & 248 & & \\
\hline Total & 17 & 52743.5 & & & & \\
\hline
\end{tabular}

'Wafer' was added to the hypothesis test as a random factor. Because the p-value was greater than the significance value of 0.05 , 'Wafer' did not have an effect on the etch rate. The p-value for the interaction term, Ratio*Power, indicated that there was a moderate interaction. However, since it was greater than 0.05 , this was ruled out as statistically significant. The p-value for ratio and power, which was 0.002 and 0.008 , respectively, indicated that both ratio and power had a significant effect on the etch rate. To determine 
how each factor affected the etch rate, Tukey's Method was utilized to examine all pairwise comparisons. The family significance rate was set at 0.05 . The Tukey test presented both confidence intervals and p-values for the user to test its significance. If the confidence interval did not contain zero, then it was significant. Likewise, if the p-value was less than 0.05 , then it was significant. Table VI summarizes the Tukey output. Significant values are shaded.

Table VI: Results from Tukey Pair-wise Comparison for Etch Rate

\begin{tabular}{|c|c|c|}
\hline \multirow{1}{*}{ Factor } & $\begin{array}{c}\text { Confidence Interval } \\
\text { Conclusion }\end{array}$ & P-value \\
\hline Partial Pressure Ratio & $\mu_{2}>\mu_{1}$ & 0.0235 \\
\cline { 2 - 3 } & $\mu_{3}>\mu_{1}$ & 0.0019 \\
\cline { 2 - 3 } & $\mu_{3}>\mu_{2}$ & 0.0384 \\
\cline { 2 - 3 } & $\mu_{200}=\mu_{100}$ & 0.8434 \\
\hline RF Power & $\mu_{300}>\mu_{100}$ & 0.0120 \\
\cline { 2 - 3 } & $\mu_{300}>\mu_{200}$ & 0.0186 \\
\cline { 2 - 3 } & \multicolumn{2}{|c|}{$\mu_{100}=\mu_{200} ; \mu_{300}>\mu_{200}$} \\
\cline { 2 - 3 } &
\end{tabular}

From the results in Table VI, increasing the content of $\mathrm{SF}_{6}$ led to an increase in the etch rate. In terms of RF power, changing the power from $100 \mathrm{~W}$ to $200 \mathrm{~W}$ did not have a significant effect. However, changing the power from 200 to 300 led to an increase in etch rate. 


\subsection{Roughness}

The sample means and standard deviations of roughness with partial pressure ratio and RF power as factors were tabulated (Tables VII and VIII).

Table VII: Descriptive Statistics of Roughness with Varying Partial Pressure Ratio

\begin{tabular}{|c|c|c|c|}
\hline $\begin{array}{c}\text { Partial Pressure } \\
\text { Ratio }\end{array}$ & Sample Size (n) & Mean (nm) \pm S.E. & Standard Deviation \\
\hline 1 & 6 & $10.73 \pm 2.79$ & 6.84 \\
\hline 2 & 6 & $56.10 \pm 9.31$ & 22.80 \\
\hline 3 & 6 & $78.20 \pm 24.4$ & 59.80 \\
\hline
\end{tabular}

Table VIII: Descriptive Statistics of Roughness with Varying RF Power

\begin{tabular}{|c|c|c|c|}
\hline RF Power (Watts) & Sample Size (n) & Mean (nm) \pm S.E. & Standard Deviation \\
\hline 100 & 6 & $51.9 \pm 20.1$ & 49.2 \\
\hline 200 & 6 & $53.9 \pm 24.3$ & 59.5 \\
\hline 300 & 6 & $39.2 \pm 12.0$ & 29.3 \\
\hline
\end{tabular}

Similar to etch rate, the hypothesis testing for roughness was the same. From the residual plots, the chosen analysis was that of roughness with the interaction removed. The ANOVA output is shown in Table IX. 
Table IX: ANOVA Output for Roughness

\begin{tabular}{|c|c|c|c|c|c|c|}
\hline Source & DF & Seq SS & Adj SS & MS & F & P \\
\hline Wafer & 5 & 11035 & 7729 & 1546 & 1.01 & 0.469 \\
\hline Ratio & 2 & 9450 & 8663 & 4331 & 2.84 & 0.117 \\
\hline Power & 2 & 2201 & 2201 & 1100 & 0.72 & 0.515 \\
\hline Error & 8 & 12211 & 12211 & 1526 & & \\
\hline Total & 17 & 34897 & & & & \\
\hline
\end{tabular}

There was one unusual observation as it had a large standardized residual. Since the pvalues for both partial-pressure ratio and RF power were greater than 0.05 , statistically, both factors did not have an effect on the roughness.

\subsection{Microscopic Images of Mask Damage}

During the profilometer measurements, there appeared to be damage or some form of debris on the aluminum mask. Of the 18 runs, this occurred in seven of the runs. They range in mild to severe. Images of this damage can be seen below. 


\subsubsection{Mild Cases}

Mild instances of aluminum mask damage occurred at varying conditions (Figures 16-18). Three of them occurred on one wafer.

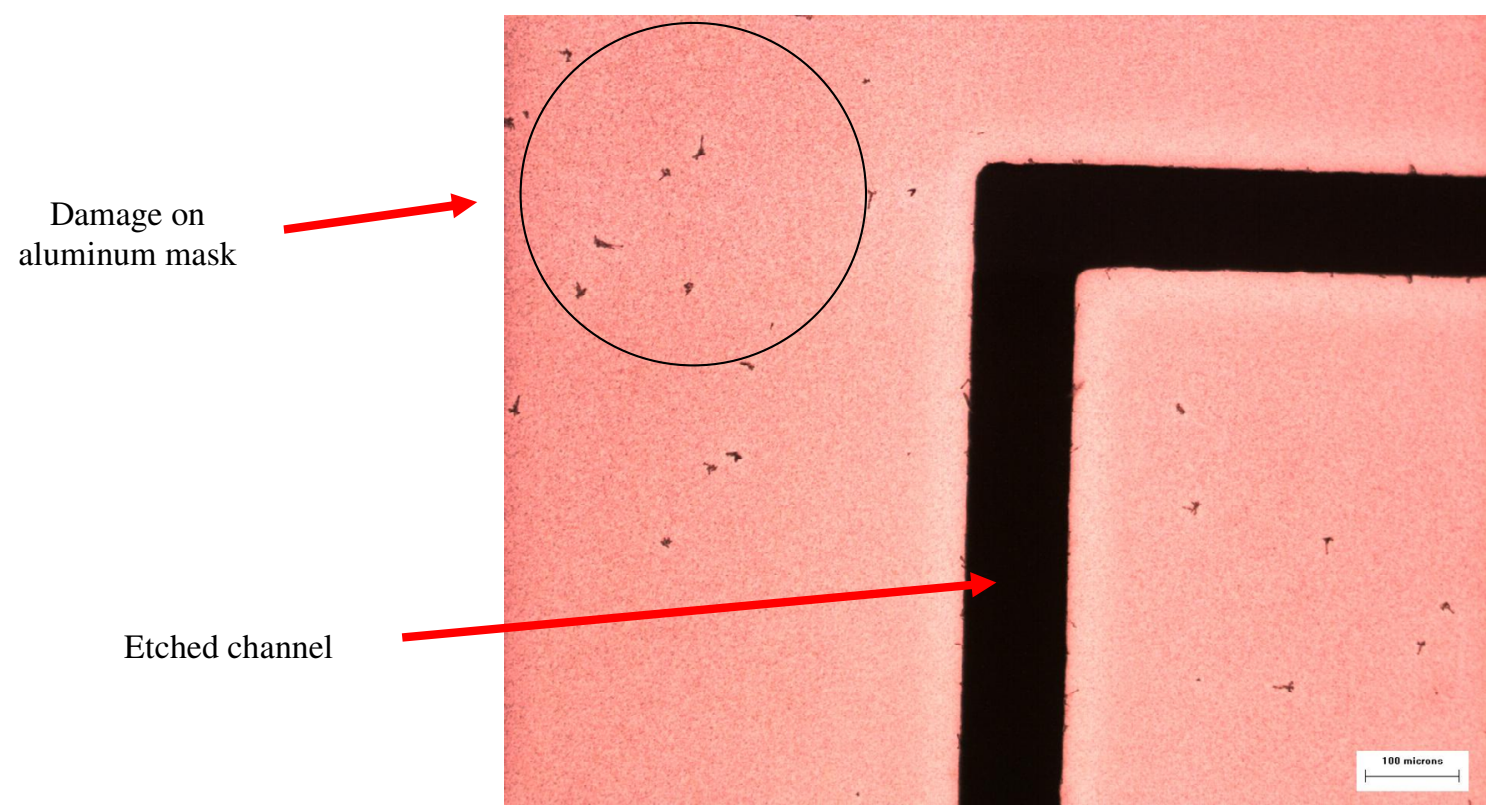

Figure 16: Microscopic image of aluminum mask damage on etched glass wafer. 50:50 partial pressure ratio, $\mathrm{RF}$ power $300 \mathrm{~W}$. 


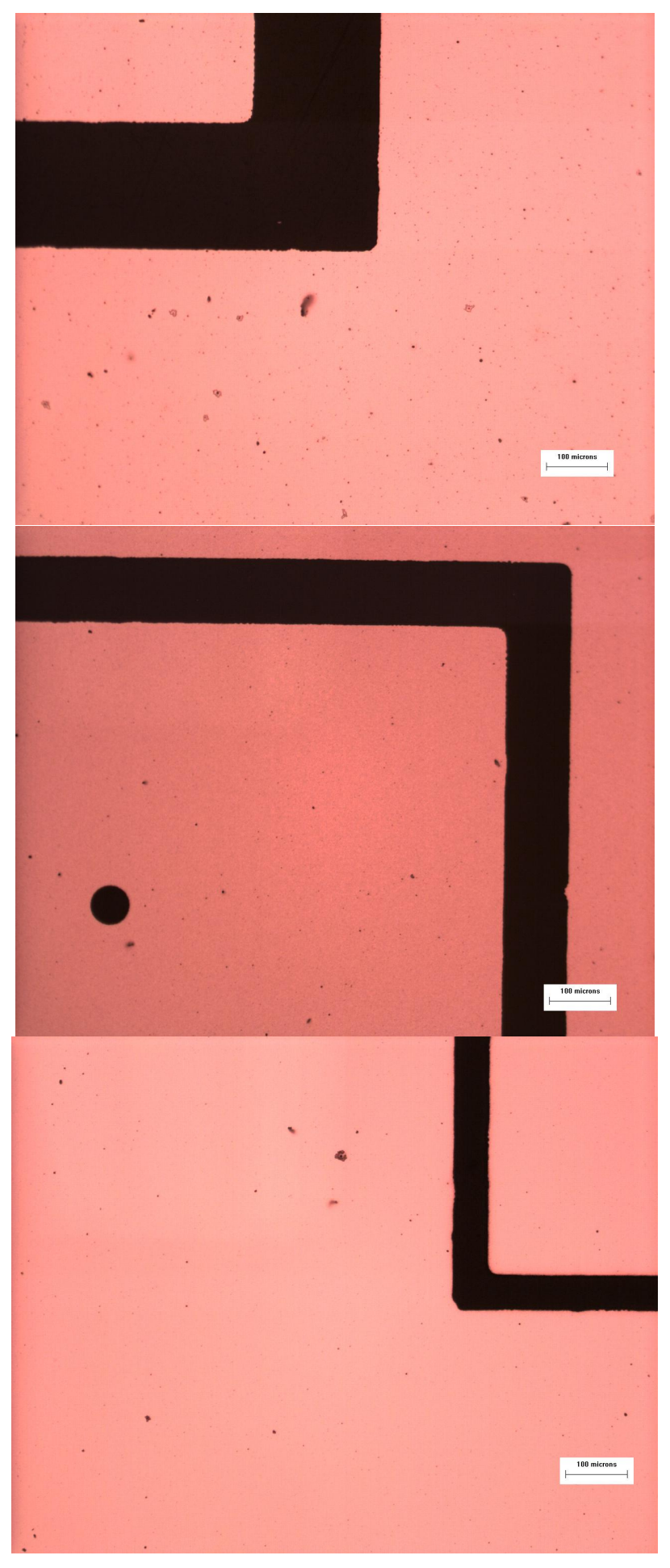

Figure 17: Damage on mask present in three runs on one wafer. Top to bottom: Partial pressure ratio 20:80/300 W, 20:80/100 W, 80:20/100 W. 


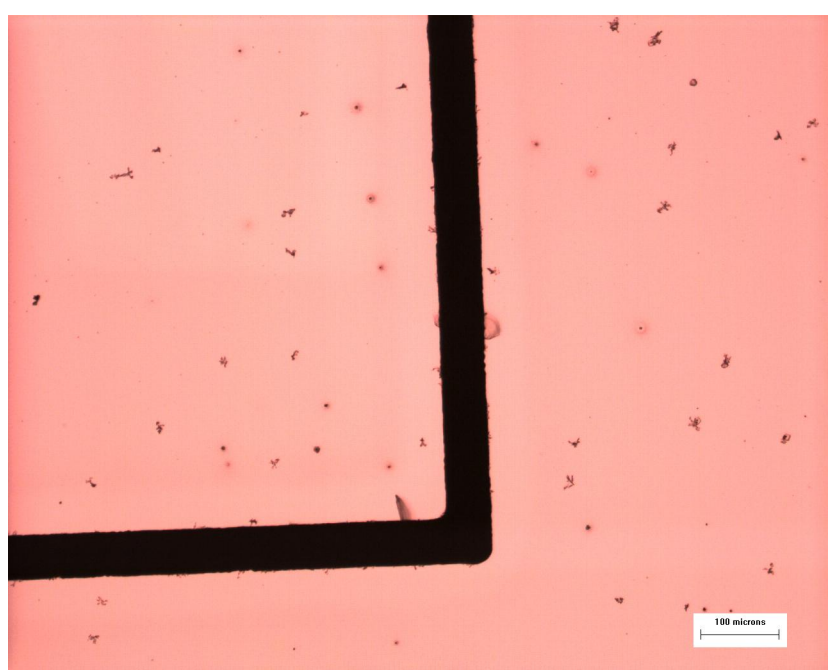

Figure 18: Damage on aluminum mask. 50:50 partial pressure ratio, RF power $300 \mathrm{~W}$.

\subsubsection{Severe Cases}

The most severe cases occurred with two of the runs (Figures 19 and 20).

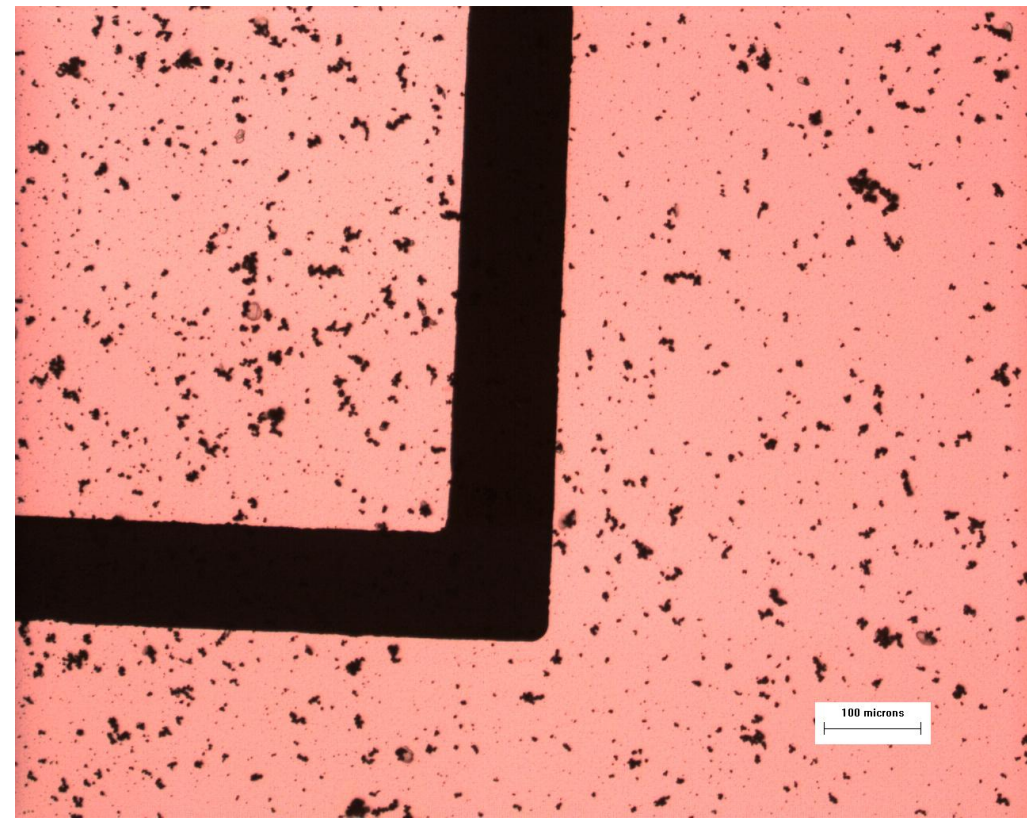

Figure 19: Severe damage on aluminum mask. 20:80 partial pressure ratio, RF power 300. 


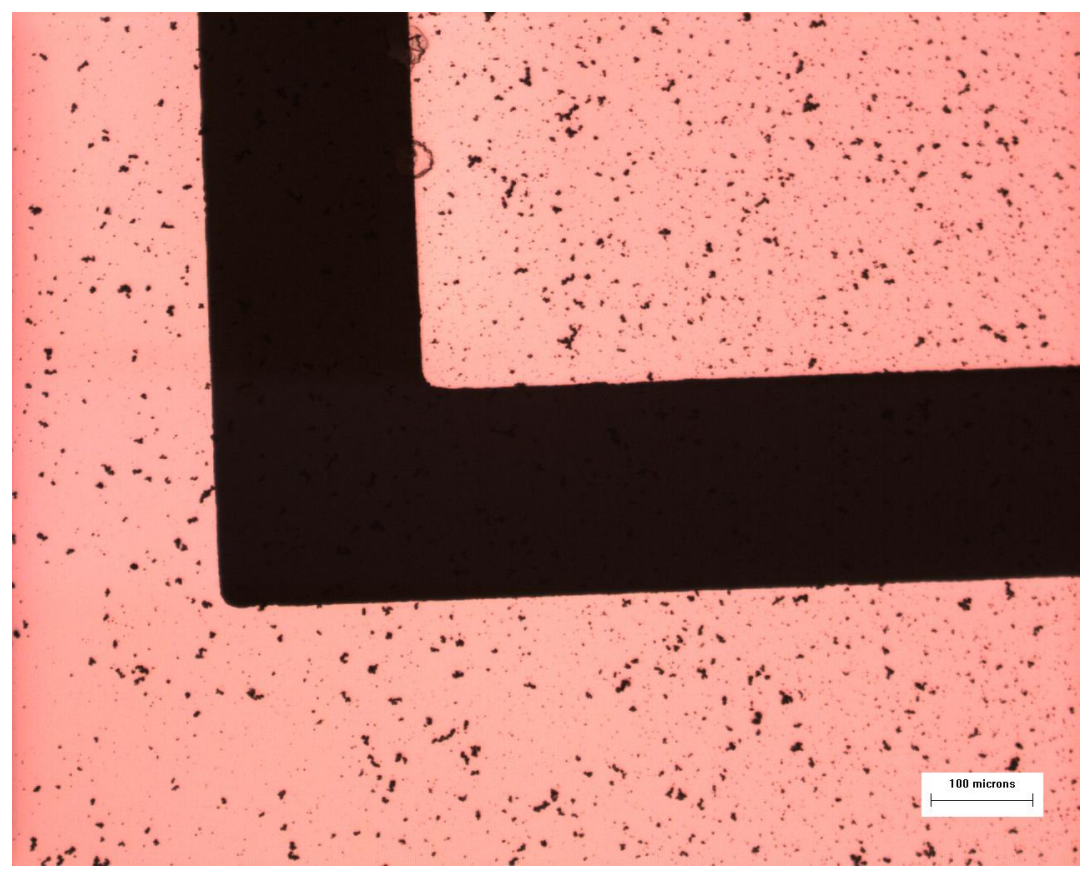

Figure 20: Damage on aluminum mask. 50:50 partial pressure ratio, $200 \mathrm{~W}$ RF power. 


\section{Discussion}

The results appeared to match that found in literature and could be explained through the physics and chemistry of etching. However, there were a couple instances where the small sample size masked any statistically discernable differences due to the treatments.

\subsection{Etch Rate}

From the Tukey Pair-wise comparison test in Table VI, an increase in the $\mathrm{SF}_{6}$ content led to an increase in etch rate. This was expected as the increase in $\mathrm{F}$ atoms was able to react

with the surface, form a volatile product, and thus remove material. The decomposition of $\mathrm{SF}_{6}$ is required to release $\mathrm{F}$ atoms to etch the glass (Equation 5) [28].

$$
\mathrm{SF}_{\mathrm{x}}+\mathrm{e}^{-} \rightarrow \mathrm{SF}_{\mathrm{x}-1}+\mathrm{F}^{-}+\mathrm{e}^{-} \quad(6 \geq \mathrm{x} \geq 1)
$$

It is known that the addition of $\mathrm{O}_{2}$ should increase etch rate due to the $\mathrm{SF}_{\mathrm{x}}+\mathrm{O}$ interaction. From Equation 4, the oxygen binds to the $\mathrm{SF}_{\mathrm{n}-1}$ radical, releasing an $\mathrm{F}$ radical. However, from the results, it appears that the $\mathrm{O}_{2}$ may have diluted the plasma.

The products of the reaction can recombine rapidly to form $\mathrm{SF}_{6}$. To etch $\mathrm{SiO}_{2}$, the free $\mathrm{F}$ radicals undergo a chemical reaction with the surface (Equations 6 and 7). At the end of the reaction, $\mathrm{SiF}_{4}$, a volatile compound, is formed and pumped out of the chamber [29]. 


$$
\begin{gathered}
\mathrm{SiO}_{2}+2 \mathrm{~F} \rightarrow \mathrm{SiF}_{2}+\mathrm{O}_{2} \\
\mathrm{SiF}_{2}+\mathrm{SiF}_{2}+\mathrm{O}_{2}+\mathrm{O}_{2} \rightarrow \mathrm{SiF}_{4}+\mathrm{Si}+2 \mathrm{O}_{2}
\end{gathered}
$$

Thus, the increase in $\mathrm{SF}_{6}: \mathrm{O}_{2}$ led to an increase in etch rate due to the addition of $\mathrm{F}$ radicals to etch the $\mathrm{SiO}_{2}$.

The Tukey's Method results for the effect of RF power indicated a statistical difference between powers 200 and $300 \mathrm{~W}$ (Table VI). Increasing the RF power meant that the energy and concentration of the ions was greater and thus more bombardment occurred. Here, the physical component of reactive-ion etching caused an increase in the etch rate. Statistically, there was no difference between powers 100 and 200 W. However, the sample means are clearly different (Table IV). This indicates that there may be a difference between the two, but the variation in the data makes it difficult for statistics to detect. This problem could be alleviated by increasing the sample size. Tukey's method starts with the calculation of the threshold value, $T$ (Equation 8).

$$
T=q_{\alpha} \sqrt{\frac{M S E}{n_{i}}}
$$

where $n_{i}=$ the size of the sample drawn from each population

$$
\begin{gathered}
q_{\alpha}=\text { right-tail statistic } \\
M S E=\text { Mean square error }
\end{gathered}
$$


The difference between two sample means, $\left|\overline{x_{i}}-\overline{x_{j}}\right|$, is compared to the threshold value.

If it exceeds $T$, then statistically, there is a difference between the means. The mean square error, shown in the equation, is the square of the standard error. The standard error is calculated by dividing the standard deviation by the square root of the sample size. Thus, increasing the amount of samples will lead to a smaller standard error. A smaller standard error would lead to a smaller mean square error, and therefore, a smaller threshold value. This makes it easier for the difference in sample means to exceed the threshold value, which would indicate a statistical difference. The small sample size made the threshold value large; it was difficult to detect a statistical difference between 100 and $200 \mathrm{~W}$. After some calculations, it was determined that given the standard deviation, approximately 12 samples were needed before a difference could be detected between the means.

\subsection{Roughness}

The ANOVA test for roughness did not reveal a statistical significance for partial pressure ratio and RF power. The sample means had a standard deviation approximately the size of the means themselves, indicating that the variability in the data made it difficult for the ANOVA test to detect a statistical difference. The p-value in an ANOVA test, which indicates statistical significance, is determined from the F-stastistic (Equation 9). 


$$
F=\frac{M S T r}{M S E}
$$

where $M S T r$ is the mean square for treatments and MSE is the mean square error

A large F-statistic would yield a lower p-value. Based on the equation, decreasing the mean square error would increase the F-statistic. Similar to the threshold value in Tukey's method, increasing the sample size would decrease the standard error, and thus the mean square error as well.

From the sample means, there may be an increase in roughness due to an increase in $\mathrm{SF}_{6}$ concentration. This may be due to the build-up of non-volatile etch products. As more F atoms were allowed to react with the surface, there was a higher likelihood that nonvolatile products were generated. These products cannot be removed through chemical means and must depend on physical bombardment. According to Metwalli and Pantano, as chemically reactive species approached the surface, volatile and non-volatile products were formed. The non-volatile species could coalesce and redeposit on the surface, acting as "micromasks." The "micromasks" prevent etching and could lead to surface roughening. For RF power, the sample means for 100 and $200 \mathrm{~W}$ are similar at 51.9 and $53.9 \mathrm{~nm}$, respectively. At $300 \mathrm{~W}$, there was a decrease in the roughness sample mean. This may have been due to the increased physical bombardment from the large RF power. The bombardment was able to remove the non-volatile products and decrease the roughness [19]. This theory was confirmed by Ichiki et al. Rough surfaces were found at low bias powers. This indicated the presence of backscattered etching products, which 
formed "micromasks." A smoother surface was attained at higher powers (Figure 21) [30].

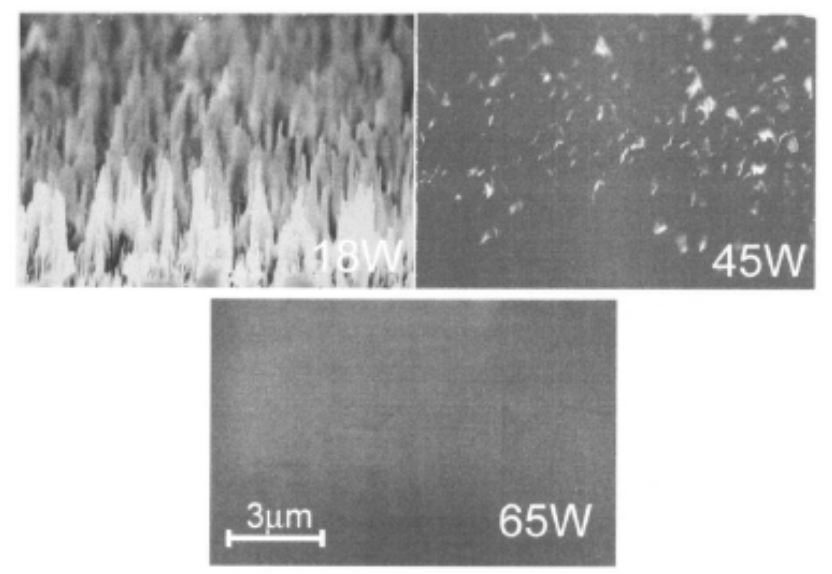

Figure 21: SEM images of Corning 7740 surfaces etched in $\mathrm{SF}_{6}$ plasmas at varying substrate bias powers [30].

XPS data confirmed the presence of non-volatile compounds on the surface at low bias powers (Figure 22). 


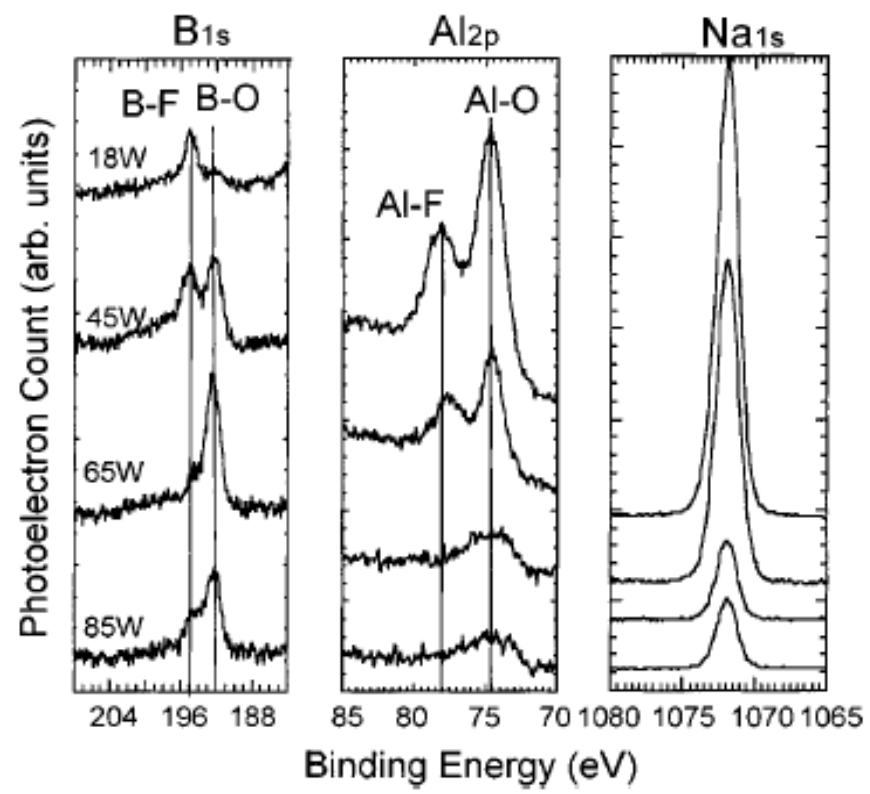

Figure 22: XPS spectra of $\mathrm{B}_{1 \mathrm{~s}}, \mathrm{Al}_{2 \mathrm{p}}$, and $\mathrm{Na}_{1 \mathrm{~s}}$ from Corning 7740 glass etched in $\mathrm{SF}_{6}$ at varying substrate bias powers [30].

The fluoride peak intensity decreased with increasing bias power and the oxide peaks remained. This showed that high powers were able to remove the non-volatile fluorides. $\mathrm{Li}$ et al. also experienced a decrease in roughness with increasing RF power. They found that the optimum power level for a smooth surface was more than $100 \mathrm{~W}$ [24].

The roughness values presented in this thesis were approximately less than $10 \%$ than those determined in other studies. This was expected because of a difference in etch depth. Maximum etch depths in this thesis were approximately 2-3 $\mu \mathrm{m}$, while those presented in literature were at least $18-20 \mu \mathrm{m}$. They etched for about 45 minutes to an hour while the glass wafers in this thesis were etched for 20 minutes. Metwalli and Pantano showed that as etching time increased, the amount of non-volatile species 
increased (Figure 8) [19]. Because they etched for a longer period of time, the higher amount of non-volatile species led to greater roughness values.

\subsection{Aluminum Mask Damage}

It was unclear as to why some of the runs caused the damage shown in Figures 16-20. It may have been due to contamination from the etching process. Glück and Höppner found that on samples etched with an aluminum mask, grass-like structures developed. They believed that the contamination occurred because aluminum did not react with the fluorine species [31]. The dark flakes on the mask could also have been etched $\mathrm{SiO}_{2}$, since they are the same color as the etched channel. To determine the exact cause of the damage would require analysis by energy-dispersive x-ray spectroscopy (EDS). EDS can be used to determine the elemental composition of the damage and this information would then lead to the cause. If the damage were due to etched pinholes, it would be difficult to determine whether it was caused by a material defect. In crystalline materials, etched pinholes may resemble the shape of the crystal structure. For example, pinholes in GaN have a hexagonal shape because of its wurtzite crystal structure. The amorphousness of glass would not provide a discernable shape in an etched pinhole. 


\section{Conclusions}

A study was conducted on the etch rate and etched surface roughness of the dry etching of borosilicate glass. The two factors tested were partial pressure ratio $\left(\mathrm{SF}_{6}: \mathrm{O}_{2}\right)$ and $\mathrm{RF}$ power. Statistically, the variation of RF power and partial pressure was found to have a significant effect on etch rate. As the ratio for $\mathrm{SF}_{6}: \mathrm{O}_{2}$ was increased, the etch rate increased. This was due to the addition of available $\mathrm{F}$ atoms to chemically etch the $\mathrm{SiO}_{2}$. An increase in RF power from 200 to $300 \mathrm{~W}$ led to an increase in etch rate; this was confirmed from a Tukey test at a $95 \%$ confidence interval. There was not a statistical difference between 100 and $200 \mathrm{~W}$. This may have been due to the variation in the data caused by a small sample size, which made it difficult for a statistical difference to be detected. The increase in RF power allowed more ionic bombardment to occur, thereby increasing the etch rate. From the ANOVA output for roughness, there was no statistical significance for partial pressure ratio and RF power. The high variability in the data may have made it difficult to discern a statistical difference between the samples. Again, the variability in the data may be due to the small sample size. From the sample means, there was a possible trend occurring. A higher $\mathrm{SF}_{6}: \mathrm{O}_{2}$ ratio may have led to a larger roughness. If it did, this may have been due to a larger amount of $\mathrm{F}$ atoms that were able to react with the surface and form non-volatile compounds. It is possible that the high RF power increased the ionic bombardment and removed the non-volatile products, thus, decreasing the roughness. It was unclear as to why there was damage on the aluminum mask for some of the runs. It may have been due to contamination from the creation of non-volatile 
products, or it was possibly etched pinholes. Determining the cause would require additional materials analysis techniques. 


\section{Future Work}

There are definitely opportunities for future work. Different factors such as aspect ratio

dependence, mask material, and pressure could be studied. In terms of response variables, undercutting could be investigated. There was an attempt to study undercutting in this thesis. However, due to a procedural error, that was not possible. To investigate what occurred in the results, XPS can be used to analyze the amount of non-volatile compounds in the etched channel. Due to limited time and resources, this could not be completed. 


\section{References}

[1] Whitesides, George M. "The Origins and the Future of Microfluidics." Nature 442 (2006): 369-73. Print.

[2] Srinivasan, Vijay, Vamsee K. Pamula, and Richard B. Fair. "An Integrated Digital Microfluidic Lab-on-a-Chip for Clinical Diagnostics on Human Physiological Fluids." Lab Chip 4 (2004): 310-15. Print.

[3] Ahn, Chong H., Jin-Woo Choi, Gregory Beaucage, Joseph H. Nevin, Jeong-Bong Lee, Aniruddha Puntambekar, and Jae Y. Lee. "Disposable Smart Lab on a Chip for Point-ofCare Clinical Diagnostics." Proceedings of the IEEE 92.1 (2004): 154-73. Print.

[4] Takabayashi, Yoshimasa, Michihisa Uemoto, Kenjiro Aoki, Tamao Odake, and Takashi Korenaga. "Development and Optimization of a Lab-on-a-Chip Device for the Measurement of Trace Nitrogen Dioxide Gas in the Atmosphere." Analyst 131 (2006): 573-78. Print.

[5] McDonald, J. C., David C. Duffy, Janelle R. Anderson, Daniel T. Chiu, Hongkai Wu, Olivier J.A. Schueller, and George M. Whitesides. "Fabrication of Microfluidic Systems in Poly(dimethylsiloxane)." Electrophoresis 21 (2000): 27-40. Print. 
[6] Ng, J. M., I. Gitlin, A. D. Stroock, and G. M. Whitesides. "Components for Integrated Poly(dimethylsiloxane) Microfluidic Systems." Electrophoresis 23.20 (2002): 3461-473. Print.

[7] Xia, Younan, and George M. Whitesides. "Soft Lithography." Annu. Rev. Mater. Sci. 28 (1998): 153-84. Print.

[8] Mata, Alvaro, Aaron J. Fleischman, and Shuvo Roy. "Characterization of Polydimethylsiloxane (PDMS) Properties for Biomedical Micro/Nanosystems." Biomedical Microdevices 7.4 (2005): 281-93. Print.

[9] Lee, Jessamine N., Cheolmin Park, and George M. Whitesides. "Solvent Compatibility of Poly(dimethylsiloxane)-Based Microfluidic Devices." Anal. Chem 75.23 (2003): 6544-554. Print.

[10] Campbell, Stephen A. Fabrication Engineering at the Micro-and Nanoscale. 3rd ed. New York: Oxford UP, 2008. Print.

[11] Williams, John. "Engineering Surfaces." Engineering Tribology. Cambridge: Cambridge Univ., 2006. 45-51. Print.

[12] Jesweit, J. "Surface Roughness II." Mech 213 Lecture 6, Surface Roughness II. Queen's University, Ontario. Lecture. 
[13] Wolf, Stanley. "Dry-Etching for ULSI." Microchip Manufacturing. Sunset Beach: Lattice, 2003. 391-409. Print.

[14] Wolf, Stanley, and Richard N. Tauber. Silicon Processing for the VLSI Era. 2nd ed. Vol. 1. Lattice, 2000. Print.

[15] Park, Sang-Kyu, Seong-Woo Seo, and Shi-Woo Rhee. "Dry Etching of Tungsten Films Using SF6 and SF6/O2 Discharges." Proceedings of the Symposium on Highly Selective Dry Etching and Damage Control. Ed. G. S. Mathad and Y. Horiike. Vol. 93-21. Pennington: Electrochemical Society, 1993. 243-54. Print.

[16] Wilkinson, C. D.W., and M. Rahman. "Dry Etching and Sputtering." Phil. Trans. R. Soc. Lond. A 362 (2004): 125-38. Print.

[17] Kingery, W. D., H. K. Bowen, and D. R. Uhlmann. "Structure of Glasses." Introduction to Ceramics. 2nd ed. New York: John Wiley \& Sons, 1976. 93105. Print.

[18] Mozzi, R. L., and B. E. Warren. "The Structure of Vitreous Silica." J. Appl. Crystallogr. 2 (1969): 164-72. Print. 
[19] Metwalli, EzzEldin, and Carlo G. Pantano. "Reactive Ion Etching of Glasses:

Composition Dependence." Nuclear Instruments and Methods in Physics Research B 207 (2003): 21-27. Print.

[20] Park, J. H., N.-E. Lee, Jaechan Lee, J. S. Park, and H. D. Park. "Deep Dry Etching of Borosilicate Glass Using SF6 and SF6/Ar Inductively Coupled Plasmas." Microelectronic Engineering 82 (2005): 119-28. Print.

[21] Akashi, T., and Y. Yoshimura. "Deep Reactive Ion Etching of Borosilicate Glass Using an Anodically Bonded Silicon Wafer As An Etching Mask." J. Micromech. Miroeng. 16 (2006): 1051-056. Print.

[22] Ronggui, Shen, and Giancarlo C. Righini. "Characterization of Reactive Ion Etching of Glass and Its Applications In Integrated Optics." J. Vac. Sci. Technol. A 9.5 (1991): 2709-712. Print.

[23] Baram, Adi, and Matan Naftali. "Dry Etching of Deep Cavities in Pyrex for MEMS Applications Using Standard Lithography." J. Micromech. Miroeng. 16 (2006): 2287-291. Print.

[24] Li, Li, Takashi Abe, and Masayoshi Esashi. "Smooth Surface Glass Etching By Deep Reactive Ion Etching with SF6 and Xe Gases." J. Vac. Sci. Technol. B 21.6 (2003): 2545-549. Print. 
[25] Thiénot, Edouard, Florian Domingo, Edmond Cambril, and Charlie Gosse. "Reactive Ion Etching of Glass for Biochip Applications: Composition Effects and Surface Damages."Microelectronic Engineering 83 (2006): 1155-158. Print.

[26] Leech, Patrick W. "Reactive Ion Etching of Quartz and Silica-Based Glasses in CF4/CHF3 Plasmas." Vacuum 55 (1999): 191-96. Print.

[27] Li, Xinghua, Takashi Abe, and Masayoshi Esashi. "Deep Reactive Ion Etching of Pyrex Glass Using SF6 Plasma." Sensors and Actuators A 87 (2001): 139-45. Print.

[28] Shih, Minliang, Wen-Jhy Lee, and Chuh-Yung Chen. "Decomposition of SF6 and H2S Mixture in Radio Frequency Plasma Environment." Ind. Eng. Chem. Res. 42 (2003): 2906-912. Print.

[29] Sajad, Batool, Parviz Parvin, and Mohamad A. Bassam. "SF6 Decomposition and Layer Formation Due to Excimer Laser Photoablation of SiO2 Surface at Gas-Solid System." J. Phys. D: Appl. Phys. 37 (2004): 3402-408. Print.

[30] Ichiki, Takanori, Yoshinari Sugiyama, Takekazu Ujiie, and Yasuhiro Horiike. "Deep Dry Etching of Borosilicate Glass Using Fluorine-Based High-Density Plasmas for Microelectromechanical System Fabrication." J. Vac. Sci. Technol. B 21.5 (2003): 2188192. Print. 
[31] Glück, B., and W. Höppner. "Etching of Silicon Trenches in CF4 Plasma Using Photoresist/Aluminum Masks." Cryst. Res. Technol. 25.3 (1990): 277-83. Print. 